\title{
Economics and GHG emission reduction of a PLA bio-refinery system-Combining bottom-up analysis with price elasticity effects
}

\author{
V. Dornburg*, A. Faaij, M. Patel, W.C. Turkenburg \\ Department of Science, Technology and Society, Copernicus Institute, Utrecht University, \\ Heidelberglaan 2, 3584 CS Utrecht, The Netherlands
}

Received 10 September 2004; accepted 15 August 2005

Available online 28 November 2005

\begin{abstract}
This paper analyses energy savings, GHG emission reductions and costs of bio-refinery systems for polylactic acid (PLA) production. The systems comprise 'multi-functional' uses of biomass resources, i.e. use of agricultural residues for energy consumption, use of by-products, and recycling and wasteto-energy recovery of materials. We evaluate the performance of these systems per kg of bio-based polymer produced and per ha of biomass production. The evaluation is done using data of Poland assuming that biomass and PLA production is embedded in a European energy and material market. First, the performance of different bio-refinery systems is investigated by means of a bottom-up chain analysis. Second, an analysis is applied that derives market prices of products and land depending on the own-price elasticity of demand. Thus, the costs of bio-refinery systems depending on the demand of land and material are determined. It is found that all PLA bio-refinery systems considered lead to net savings of non-renewable energy consumption of 70-220 GJ/(ha yr) and net GHG emission reductions of 3-17 $\mathrm{Mg} \mathrm{CO}_{2 \mathrm{eq}} /$ (ha yr). Most of these PLA bio-refinery systems lead to net costs for the overall system of up to $4600 € /($ ha yr). PLA production from short rotation wood leads to net benefits of about $1100 € /($ ha yr) if a high amount of a high value product, i.e. fibres, is produced. Multi-functionality is necessary to ensure the viability of PLA bio-refinery systems from biomass with regard to energy savings and GHG emission reduction. However, the multi-functional use of biomass does not contribute much to overall incomes. Multifunctional biomass use - especially the use of biomass residues for energy consumption - contributes significantly to savings of nonrenewable energy sources. Own-price elasticity of the demand for materials influences the overall
\end{abstract}

\footnotetext{
* Corresponding author.

E-mail address: V.Dornburg@ chem.uu.nl (V. Dornburg).
} 
costs of the bio-refinery system strongly. The own-price elasticity of land demand markets could become important if bio-refineries are introduced on a large scale.

(c) 2005 Elsevier B.V. All rights reserved.

Keywords: Polylactic acid (PLA); Multi-functional biomass use; System analysis; Elasticity; Recycling

\section{Introduction}

Biomass is suitable for many material and energy applications, e.g. construction materials, chemicals, liquid fuels or electricity. One of the reasons to investigate the potential use of biomass for such applications is the reduction of greenhouse gas (GHG) emissions, especially $\mathrm{CO}_{2}$. These reductions go along with the replacement of fossil fuels by biomass, provided that the biomass is produced in a sustainable way. In this context, the potential savings of non-renewable fuels, the resulting GHG emission reductions and the associated costs are key indicators to evaluate the efficiency of biomass use. This proves to be a complex issue in which many aspects play an important role, e.g. the choice between energy and material applications, the reference systems that are replaced by biomass use and the timeframe of the analysis, see Dornburg and Faaij (2005). In addition, if biomass is used in large amounts in order to contribute significantly to GHG emission reduction, it has to be cultivated requiring relative large areas of agricultural land. Consequently, the amount of agricultural land for biomass production is a decisive parameter as well.

Given the importance of low costs and of a high efficiency of land use for GHG emission reduction, optimising the performance of biomass systems is vital for successful deployment at large scale. Many options to improve the performance of biomass systems deal with parts of the system; for example the development of more efficient energy crop production or increasing the energetic efficiency of conversion technologies. However, to optimise biomass systems also multi-functional uses of biomass resources can be applied, e.g. multiproduct use and cascading. Multi-product use is defined as using different parts of a biomass resource for different applications. These applications can cover a broad range of materials and energy carriers. Cascading is defined as using biomass resources sequentially for several material applications ending typically with an energy conversion step to fuels, heat and/or electricity.

A particular type of multi-functional biomass system, namely the so-called 'bio-refinery', has recently received much attention in literature. This term is derived from petroleum refineries that maximise the economic benefits by obtaining a diverse mix of products from their feedstock. The concept of 'bio-refinery' is not well defined though and it can comprise various processes such as production of fodder from a crop (Annetts and Audsley, 2003) or pyrolysis of biomass (Scott et al., 1997). In literature, the term 'bio-refinery' is for example defined as the production of various products with innovative technology (Benjamin and Weenen, 2000) or the production of fuels and chemicals (Elliot, 2004) from biomass resources. In general, bio-refineries are considered to produce a range of products (see e.g. Benjamin and Weenen, 2000; DTO, 1997; Elliot, 2004; NRC, 1999; Wyman, 2003). 
Many definitions explicitly include the production of chemicals or fuels in analogy to the petrochemical refinery (e.g. Elliot, 2004; Scott et al., 1997; Wyman, 2003).

Bio-refineries as referred to in this study combine two aspects of multi-functional biomass systems. The first aspect is the use of parts of a whole crop to make different products. The second aspect is cascading, i.e. recycling of these products (usually by so-called downcycling) and finally converting their wastes to energy carriers.

It has been indicated in earlier studies that multi-product use and cascading may improve the efficiency of biomass utilisation with regard to GHG emission reductions, energy savings and costs (Dornburg and Faaij, 2005; Dornburg et al., 2005). Wyman (2003) has carried out an economic analysis of a bio-refinery producing fuels and chemicals from sugar identifying possible benefits of multi-product use. These studies are focused on parts of bio-refinery systems, i.e. multi-product use or cascading. If the parts involved would be incorporated in a more complex bio-refinery system as outlined above, the overall performance may be different than the simple sum of performances. For example, material recycling might on the one hand reduce process energy demand of material production. On the other hand, this reduced process energy demand might lead to excess heat produced from biomass residues that cannot be used if there is no additional heat demand in the vicinity of the facility. If biomass materials are recycled, one might assume that respective reference materials will also be recycled. This leads to different benefits of the biomass system compared to a "cradle-to-factory-gate" analysis of material production. So far, however, in scientific literature little attention has been paid to quantifying the performance benefits of more complex bio-refinery systems.

The economics of a bio-refinery system depend on the above-mentioned factors, but also on its scale. This is partly due to the well-studied mechanisms of economies of scale of conversion processes and equipment use (see e.g. Faaij et al., 1998), and the logistics of biomass supply (see e.g. Aden et al., 2002; Hamelinck, 2004). Another mechanism influencing the economic performance is that the size of the market and the amount of products and inputs (in particular land) in the bio-refinery system determine the market prices of inputs and outputs. These changes of market prices can influence the economic efficiency of biomass systems significantly (Dornburg et al., 2005; Green, 2000; Wyman, 2003). There has been considerable interest in the interactions between biomass utilisation and market mechanisms. Equilibrium models have been used to investigate the demand and supply of various products as a function of market prices. For example, Walsh (2000) modelled demand and supply of (biomass) fibres in the USA as function of biomass material prices. Azar and Berndes (1999) estimated market prices of food as a function of carbon emissions penalties and subsequent demands for biomass and agricultural land. Gielen et al. (2003) estimated the global demand of biomass for energy, food and materials depending on GHG mitigation policies. However, this type of studies does not analyse market prices in relation to the supply, i.e. scale of a biomass material system and thus, do not quantify the effect material and land markets can have on the costs of a certain biomass system as determined by technological bottom-up analysis. Studies addressing this subject could not be identified in scientific literature.

In conclusion, multi-functional bio-refinery systems may help to increase the performance of biomass systems, but potential quantitative benefits have been poorly studied. Consequently, the following research question is essential: What are potential quantitative 
benefits of multi-functional bio-refinery systems with regard to GHG emission reductions, savings of non-renewable energy consumption and costs in relation to production scale and market volumes?

Two factors play a key role in this question:

1. The set-up of the bio-refinery system, e.g. by-product use, recycling rates, etc.

2. The structure of the markets the bio-refinery system takes part in, i.e. the market for final products, for by-products and for agricultural land.

To answer the research question while taking into account these key factors, we carried out a case study. Subject of the case study is a bio-refinery producing bio-based polymers, i.e. polylactic acid (PLA). A previous study has shown that bio-based polymer production has an interesting potential for energy savings and GHG emission reductions with regard to agricultural land use (Dornburg et al., 2003). Out of the group of bio-based polymers, PLA has been selected, because it is the only commercially produced biobased polymer suitable for bulk application. Currently, PLA is mainly used for packaging applications. The global production capacity is about 0.2 million tonnes per year (Crank et al., 2004) compared to 19 million tonnes per year of polyethylene (PE) (UN, 2002). As PLA could partly replace PE and other large volume petrochemical polymers like polyethylene teraphthalate (PET), it has the potential to contribute significantly to savings of non-renewable energy consumption and to GHG emission reduction.

In our case study, a whole crop is defined as input for the production system. Consequently, all parts of the crop are used for the production of PLA, by-products (fodder), or energy (electricity and heat). This is how the aspect of multi-product use is included in the system. In addition, parts of the PLA products are recycled after their use and other parts are digested or incinerated with energy recovery. Thus, cascading is part of our PLA bio-refinery system.

In the first place, the performance of the bio-refinery system in terms of GHG emission reduction, non-renewable energy saving and costs are calculated by means of a bottom-up analysis. These parameters are presented both per kg of bio-based polymer produced and per ha and year of agricultural land needed for biomass production. Several configurations of the bio-refinery system (e.g. kind of crop production system, recycling rates, kind of products) are investigated such that the influence of the structure of the bio-refinery system on the performance can be analysed. In the second place, market prices of products and land depending on the scale of the bio-refinery are determined by own-price elasticity. By this, the overall economic performance of the bio-refinery system in relation to elastic markets of products and land can be determined.

Geographically the case study is situated in Poland. Currently, PLA production takes place mainly in the U.S. while several initiatives for PLA production exist in Asia. This raises the question whether such a system may also have potential in Europe. One argument is that the Eastern European states ${ }^{1}$ that accessed the European Union in May 2004 are particularly interesting for new biomass systems, because of relative low biomass production

\footnotetext{
${ }^{1}$ The Czech Republic, Estonia, Hungary, Latvia, Lithuania, Poland, the Slovak Republic, and Slovenia joined the European Union on 1 May 2004.
} 
costs, relative high available land surfaces and an agricultural system with low productivity being in transition (FAO, 2003; Skarzynska and Augustynska-Grzymek, 2000).

This paper is structured as follows: Section 2 describes the methodology for the chain analysis of the bio-refinery system and the methodology to analyse the elasticity of markets the bio-refinery system is embedded in. Section 3 describes the case of a PLA production bio-refinery system including input data for the analysis. The results of the analysis are presented in Section 4: the performance of the PLA production system depending on the system configurations and the GHG mitigation costs in relation to the scale of the PLA production system with and without market influences. Sections 5 and 6 contain discussion and conclusions.

\section{Methodology}

The analysis of the bio-refinery system is carried out in two distinct steps as presented in Fig. 1. In the first place, GHG emission reductions, savings of non-renewable energy consumption and overall costs of the bio-refinery system are calculated. These calculations are performed for different configurations of the PLA bio-refinery system as described in Sections 3 and 4. Subsequently the performance of these configurations is compared and moreover, GHG mitigation costs are analysed in relation to scale by chain analyses including economies of scale. In the second place, GHG mitigation costs in relation to scale are determined, taking into account variable market prices for land and products. These market prices are derived from market analysis using demand elasticity. Thus, the influence of the market on the results of the chain analysis can be singled out. Following, the methodologies of the chain and market analyses applied in this study are described in detail.

\subsection{Chain analysis}

In the chain analysis, the performance of a bio-refinery system is investigated. Or rather, savings of non-renewable energy consumption, GHG emission reductions and costs are

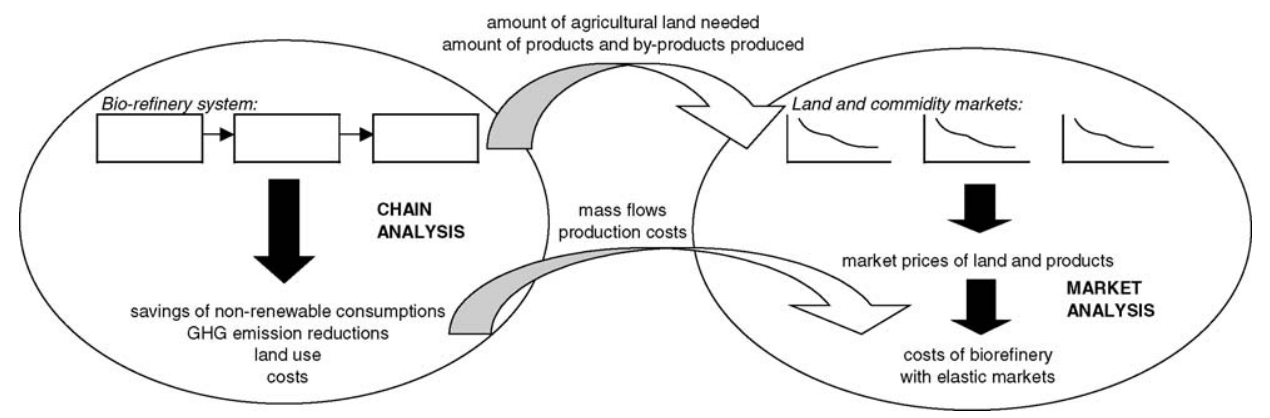

Fig. 1. Approach to investigate bio-refinery systems - a combination of a bottom-up analysis and an analysis of elastic markets. 

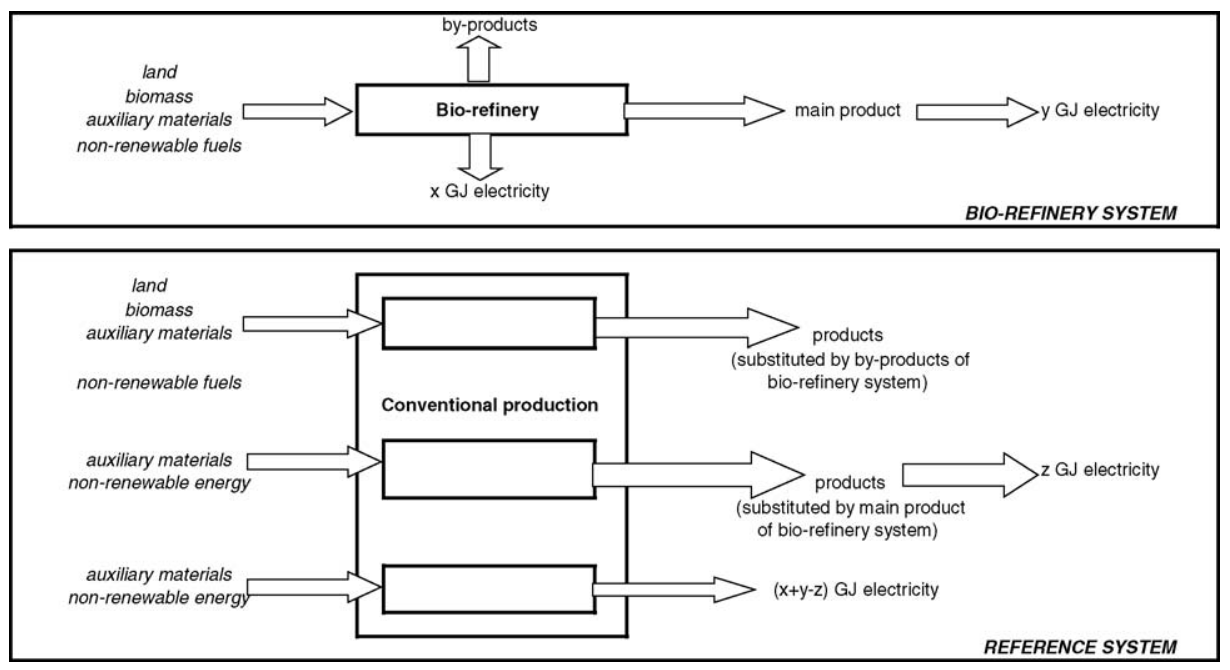

Fig. 2. Schematic overview of a bio-refinery system and its reference system.

calculated. These parameters are related to either the amount of main product that is produced, i.e. in our case study the amount of bio-based polymer, or to the area of land used for biomass production.

In order to determine savings of non-renewable energy consumption and GHG emission reductions of the bio-refinery system, a reference system for comparison needs to be defined. Fig. 2 shows schematically the bio-refinery system and the reference system belonging to it. Basis of the comparison is that all outputs of the bio-refinery system substitute equivalent products from the reference system. These outputs of the bio-refinery system are the main product and by-products (both are usually materials); electricity from biomass residues ${ }^{2}$; and electricity that is recovered by waste treatment of the main product. As for the main products in the bio-refinery system, the main product in the reference system is incinerated with electricity recovery after its end of life. However, by-products in our case study are fodder products, which cannot substitute any fossil reference products, but substitute other conventional fodder products. Consequently, biomass and land are inputs for these fodder products in the reference system. A more detailed description of products and substitution reference products is given in the following section on the PLA bio-refinery system regarded.

To calculate savings of non-renewable energy consumption of the bio-refinery, the energy uses of all parts of the bio-refinery system, e.g. biomass production, main product production, waste treatment, etc., are added up and subtracted from the sum of energy uses in the reference system. Overall GHG emission reductions obtained by the bio-refinery system are calculated like the savings of non-renewable energy consumption. In general, GHG emissions of auxiliary material, reference material and energy carrier production are calculated from life cycle analysis data. These data take into account direct and indirect emissions of

\footnotetext{
${ }^{2}$ Heat that is produced from residues is assumed to be used within the bio-refinery, but is not considered as an output that is used outside the facility.
} 
greenhouse gases summarised as $\mathrm{CO}_{2}$ equivalents in terms of global warming potential. For the production of biomass, direct and indirect GHG emissions of inputs, e.g. machine use, fertilisers, seeds, etc., are considered. Also, $\mathrm{N}_{2} \mathrm{O}$ emissions from the application of $\mathrm{N}$-fertiliser are taken into account, while $\mathrm{CH}_{4}$ emission from agricultural production are small and therefore, neglected.

Contrary to savings of non-renewable energy consumption and GHG emissions reductions, costs are not calculated by means of substitution products. Instead, revenues of products, by-products and bio-energy produced are based on their respective market values.

Finally, land demand of the bio-refinery system is the area of agricultural land used for the production of its biomass inputs. In the reference system, this agricultural land is not used for crop production. From this land use for biomass production, the agricultural land use in the reference system (for the production of products that are substituted by by-product from the bio-refinery) is subtracted.

To calculate the performance characteristics of bio-refinery systems in comparison to the reference system, input data from statistics and scientific literature are used. For every process in the system, e.g. PLA production from grain or waste incineration, inputs and outputs, e.g. land, fuel, steam, electricity, auxiliary materials and products are defined. These inputs and outputs are then converted to primary energy consumptions and GHG emissions by conversion factors from life cycle analysis studies, e.g. primary energy consumptions per $\mathrm{kg}$ of artificial fertiliser or GHG emissions per GJ electricity used. Cost data refer to the whole process, e.g. euro per kg PLA produced from grain or euro per kg waste treated. A detailed description of input data is presented in Section 3.

The geographical scope of our case study covers Poland and, thus, biomass and PLA production takes place there. Consequently, data on biomass production and agricultural land refers specifically to Poland. However, in our study other input data (such as energy mixes, production of reference products or material markets) refer to the European average situation. This is due to the fact, that non-biomass input of PLA production, e.g. electricity will rather originate from a European market than from Poland only. Moreover, products of the bio-refinery system will substitute products from the European market, too.

\subsection{Market analysis}

In order to analyse the market price changes of land and products of the bio-refinery system in relation to its scale of production, demand curves are applied. Demand curves describe the relation between demand and market price. In other words, they define which amount of a product could be sold for a certain price or vice versa. This leads us to the problem, how demand curves can be employed to determine market prices of land and product of a bio-refinery in relation to the size of the market demand and supply. Here, two cases are distinguished. First, the case is investigated for products that have a variable supply, i.e. different amounts of these products could be supplied by adapting the production capacity. Second, the case is discussed for land that has a fixed supply, i.e. the amount of agricultural land is limited to the total amount of agricultural land available.

The first case is presented in Fig. 3. Typically, in an ideal market the price and amount of a commodity are at equilibrium at $P_{\text {eq }}$ and $Q_{\text {eq }}$. In other words, the market price of a 


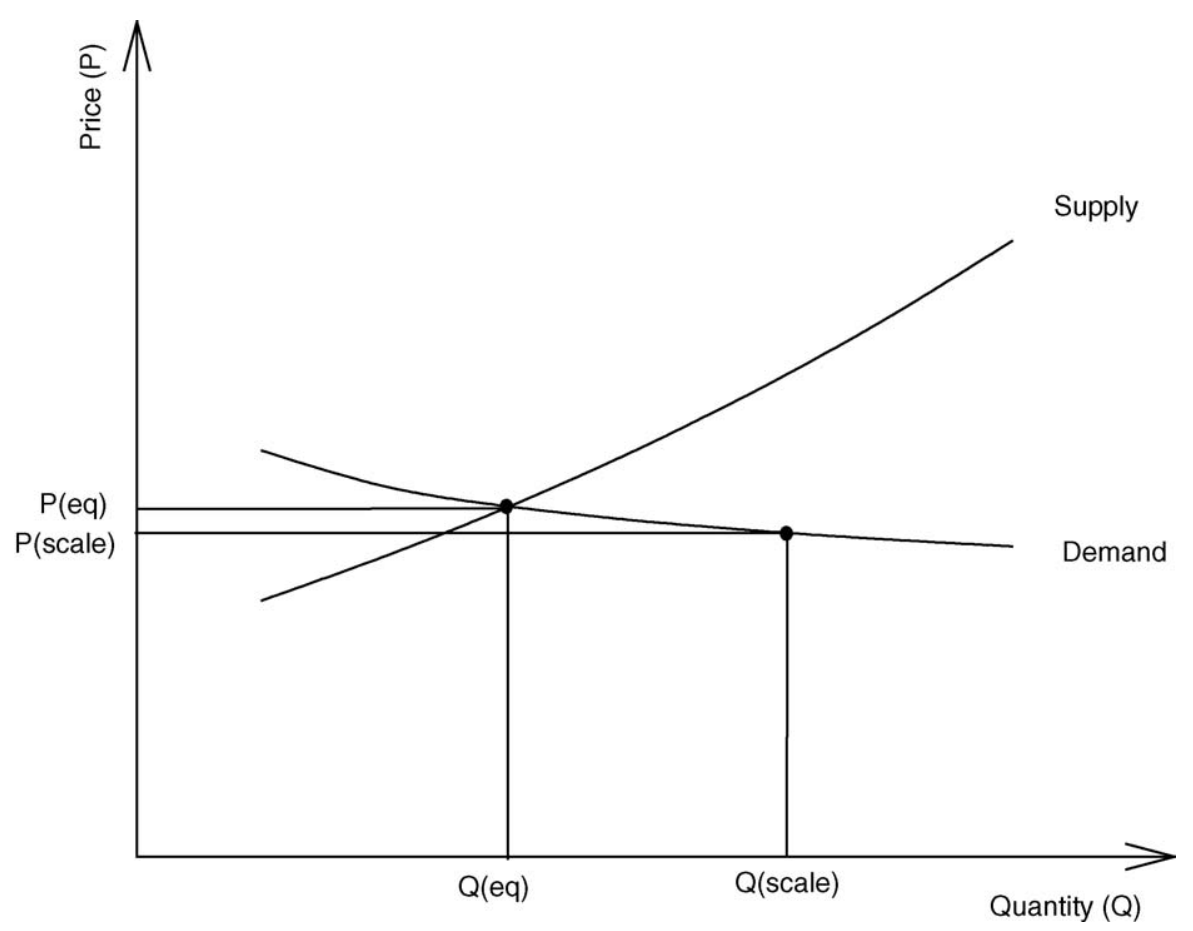

Fig. 3. Equilibrium price $P_{\mathrm{eq}}$ and quantity $Q_{\mathrm{eq}}$ of a commodity with variable supply and its new price $P_{\text {scale }}$ if an increased quantity $Q_{\text {scale }}$ is produced.

commodity in an ideal market equals its marginal production costs. If the production of a commodity is increased to $Q_{\text {scale }}$, for example by installing additional facilities, the market price decreases to $P_{\text {scale }}$ in the short term. This new market price is the price that corresponds to the new total amount of production on the demand curve. However, on the long term markets will return to a new equilibrium.

The second case is depicted in Fig. 4. Here, the commodity, i.e. agricultural land, has a fixed supply. All available agricultural land $Q_{\text {eq }}$ is already used at its equilibrium price $P_{\text {eq }}$. The demand for land increases to $Q_{\text {biomass }}$, if agricultural land is needed for biomass production. However, as no more agricultural land is available, the demand curve shifts with this additional demand. The new market price of land can be determined by the intersection of this shifted demand curve with the supply curve. As a consequence, the market price of land increases if additional agricultural land is needed for the production of biomass.

Thus, prices of agricultural land and of bio-refinery products are determined by using demand curves in this analysis. Generally, different shapes of demand curves relating demand to market prices are conceivable. A standard form of a demand curve is defined by Eq. (1) (Franssen, 1999)

$$
P(Q)=C Q^{1 / \varepsilon}
$$




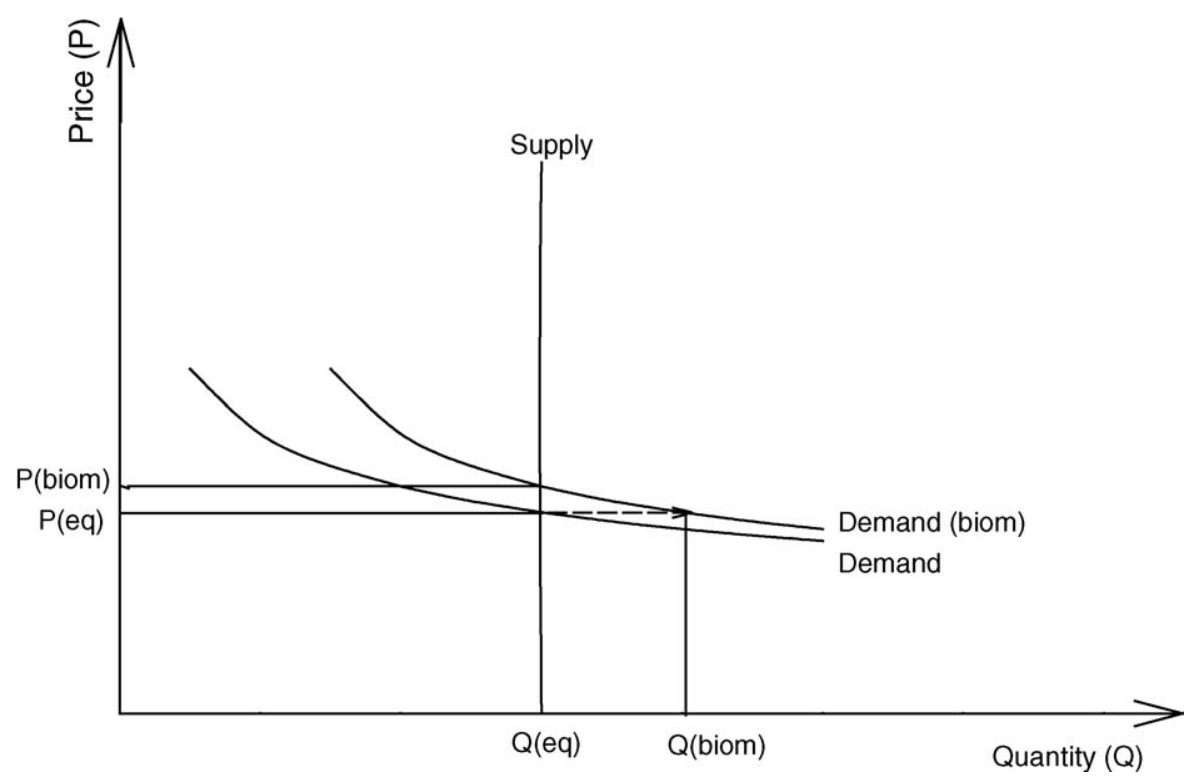

Fig. 4. Equilibrium price $P_{\mathrm{eq}}$ and quantity $Q_{\mathrm{eq}}$ of a commodity with fixed supply - e.g. agricultural land - and its new price $P_{\text {biomass }}$ if an increased quantity $Q_{\text {biomass }}$ is demanded.

where $P$ is the price of commodity, $Q$ the quantity of commodity, $C$ the constant and $\varepsilon$ is the own-price elasticity of demand.

In this formula, the own-price elasticity $\varepsilon$ is a measure of the percentage changes of price in relation to the percentage changes of demand at current demand and current market price. The own-price elasticity is typically a negative constant for a commodity. The constant $C$ is a factor that translates these percentage changes to quantities and prices. If the own-price elasticity of a commodity is known, this constant $C$ can be derived from the current demand (i.e. amount of commodity sold) and the current market price. In this article, we will use this type of demand curve to determine what change of price may be induced by a change of quantity of the commodity.

With regard to own-price elasticity, the demand curve of a commodity depends on many factors, e.g. availability of substitution possibilities, share of budget devoted to the product, kind of product, time horizon and geographical scale (Franssen, 1999). Demand curves can be derived econometrically from empirical data (e.g. time series analysis or cross-sectional analysis) or economic models. These are top-down models that simulate the production in several sectors taking into account factors, like investment, labour, cross-price elasticity, etc.

However, it is beyond the scope of our study to determine demand curves for a bio-refinery system by econometrics or macro-economic models. Therefore, a review of own-price elasticity for the demand of land and for products of the bio-refinery as discussed in scientific literature, is the basis of own-price elasticity used in our study; see Section 3.7. 


\section{PLA bio-refinery system}

The PLA bio-refinery system that is investigated in this study is presented in Fig. 5. It consists of several main components, i.e. production of biomass, PLA and bio-energy, use of end products, recycling and waste treatment. In this article, specific outlines of the components, e.g. kind of crop, recycling technology or waste treatment, are selected in order to investigate the performance of different system designs. The selected components of the PLA bio-refinery system and associated input data are described in the following sections. In addition, input data for the market analysis is discussed in the last section of this article.

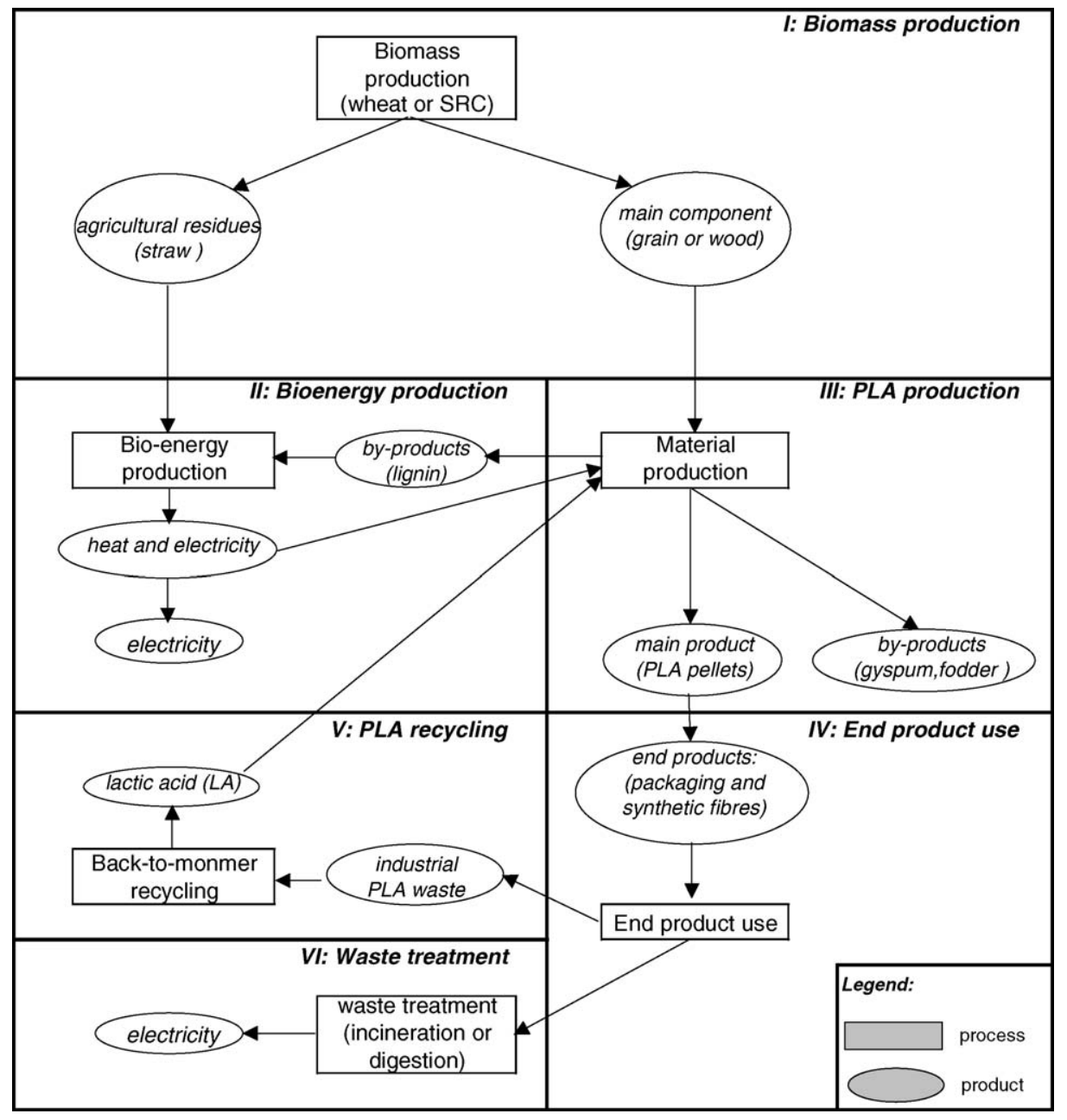

Fig. 5. PLA bio-refinery system with either wheat or wood as feedstock. 
Table 1

Input data on agricultural land for different land quality categories

\begin{tabular}{llllll}
\hline Amount (million ha) & \multicolumn{5}{l}{ Rent $(€ /(\text { ha yr }))^{\mathrm{a}}$} \\
\hline Low quality $^{\mathrm{b}}$ & Medium quality $^{\mathrm{b}}$ & High quality $^{\mathrm{b}}$ & Low quality $^{\mathrm{a}}$ & Medium quality $^{\mathrm{a}}$ & High quality $^{\mathrm{a}}$ \\
\hline 4.1 & 8.5 & 2.7 & 27 & 33 & 39 \\
\hline
\end{tabular}

${ }^{a}$ Land rents for medium quality lands are average rents paid for land for wheat production, which is the crops with the highest land rents in Poland. On the other hand, lower land prices refer to land used for rye production, which is a crop with low land rents. The difference between medium and low quality land, i.e. $6 € /($ ha yr) has been added to medium quality land rents to estimate high quality land rents (FAO, 2003).

${ }^{\mathrm{b}}$ Quality factors are divided by land valuation values, which are made up of soil quality, agro climate, relief and soil amelioration. While the average land valorisation value for Western Europe is defined as 100, the average for Poland is 67 (FAO, 2003). We defined land with a valorisation value of 55-63 as low quality, of 64-72 as medium quality and of 73-81 as high quality.

\subsection{Biomass production}

PLA can be either produced from starch or from ligno-cellulose plants. In this study, wheat and short rotation (SR) wood are considered. We focus on these crops, because of existing agricultural experience and the possibility of obtaining high yields in Poland.

Data on agricultural land and crop production are presented in Tables 1 and 2. The figures refer to the situation in Poland. Crop yields are given for different qualities of agricultural land. For that purpose, agricultural land is divided into three categories of low, medium and high quality lands by means of 'land valorisation values' on a provincial level (FAO, 2003). In addition, crop yields, costs, non-renewable energy consumption and GHG emissions of crop production are differentiated between intensities of agricultural production, i.e. intensive, average and non-intensive.

Wheat yields for average production intensity are representative for those parts of Poland where agricultural practice is comparable to Western European standards. Wheat yields of non-intensive production are yields in not intensively managed areas of Poland. Finally, wheat yields of intensive production are the potentially obtainable yields (FAO, 2003). Energy use, costs and GHG emissions of wheat production are based on Polish agricultural statistics as discussed in Dornburg et al. (2005).

As short rotation wood is not produced on a large scale in Poland, wood yields are based on experimental plots and adapted to different production intensities by factors obtained from Polish wheat production (Szczukowski et al., 1998). Also inputs of wood production are based on experimental plot data (Szczukowski et al., 2001).

With the data given in Tables 1 and 2, production costs of about $51 € / \mathrm{Mg}$ wheat and $65 € / \mathrm{Mg}$ short rotation wood are found on medium quality land and normal intensity of agricultural production. For a more detailed discussion of crop production input data, see Dornburg et al. (2005).

\subsection{Bio-energy}

Depending on the crop, either straw (from wheat) or lignin (from short rotation wood) is combusted for the production of steam and electricity. It is assumed that this steam and 
Table 2

Input data on crop production

\begin{tabular}{|c|c|c|c|c|c|c|}
\hline \multirow[t]{2}{*}{ Parameter } & \multicolumn{3}{|l|}{ Winter wheat } & \multicolumn{3}{|c|}{ Short rotation wood } \\
\hline & Non-intensive & Average & Intensive & Non-intensive & Average & Intensive \\
\hline \multicolumn{7}{|l|}{ Variation crop production system } \\
\hline Energy use $\left(\mathrm{GJ}_{\mathrm{p}} /(\right.$ ha yr $\left.)\right)$ & $6.9^{\mathrm{a}}$ & $8.9^{\mathrm{a}}$ & $10.9^{\mathrm{a}}$ & $10.7^{\mathrm{b}}$ & $13.2^{\mathrm{b}}$ & $15.7^{\mathrm{b}}$ \\
\hline $\begin{array}{l}\text { GHG emissions } \\
\qquad\left(\mathrm{kg} \mathrm{CO}_{2 \mathrm{eq}} /(\text { ha yr })\right)\end{array}$ & $1350^{\mathrm{a}}$ & $1670^{\mathrm{a}}$ & $1990^{\mathrm{a}}$ & $1050^{\mathrm{b}}$ & $1370^{\mathrm{b}}$ & $1690^{\mathrm{b}}$ \\
\hline Production costs $(€ /($ ha yr $))$ & $412^{\mathrm{a}}$ & $462^{\mathrm{a}}$ & $512^{\mathrm{a}}$ & $237^{\mathrm{b}}$ & $262^{\mathrm{b}}$ & $287^{\mathrm{b}}$ \\
\hline Factor crop yield & $0.75^{\mathrm{c}}$ & $1^{\mathrm{c}}$ & $1.25^{\mathrm{c}}$ & $0.75^{\mathrm{c}}$ & $1^{\mathrm{c}}$ & $1.25^{\mathrm{c}}$ \\
\hline \multirow[t]{2}{*}{ Factor straw yield } & $0.75^{\mathrm{c}}$ & $1^{\mathrm{c}}$ & $1.25^{\mathrm{c}}$ & - & - & - \\
\hline & Low & Medium & High & Low & Medium & High \\
\hline \multicolumn{7}{|l|}{ Variation agricultural land quality } \\
\hline Crop yields (Mg/(ha yr)) & $3.9^{\mathrm{d}}$ & $4.4^{\mathrm{d}}$ & $4.9^{\mathrm{d}}$ & $4.8^{\mathrm{e}}$ & $5.8^{\mathrm{e}}$ & $7.0^{\mathrm{e}}$ \\
\hline Straw yields (ton/(ha yr)) & $3.5^{\mathrm{f}}$ & $3.9^{\mathrm{f}}$ & $4.4^{\mathrm{f}}$ & - & & \\
\hline
\end{tabular}

$\mathrm{GJ}_{\mathrm{p}}$ : Giga Joules primary.

a Average intensity inputs are taken from Dornburg et al. (2005). The difference in fertilizer consumption between non-intensive and normal agricultural practice is about $25 \mathrm{~kg} \mathrm{NPK} /$ (ha yr) this is equivalent to $7.8 € /$ (ha yr) (FAO, 2003), $0.57 \mathrm{GJ} /$ (ha yr) and $207 \mathrm{~kg} \mathrm{CO}_{2 \mathrm{eq}} /$ (ha yr) (Biewinga and Bijl, 1996). The respective difference in fertilizer use between normal and intensive agricultural practice is about $30 \mathrm{~kg} \mathrm{NPK} /($ ha yr) $(\mathrm{FAO}, 2003)$ or $7.8 € /($ ha yr) (FAO, 2003). Including the variation of machine use, we assumed differences between normal and more extreme agricultural practice to be about $50 € /$ (ha yr), $2 \mathrm{GJ} /$ (ha yr) and $320 \mathrm{~kg} \mathrm{CO} 2 \mathrm{eq} /($ ha yr).

${ }^{\mathrm{b}}$ Inputs and costs of average production are taken from Dornburg et al. (2005). Because costs of SR wood production with average intensity are lower than cost of wheat production, lower cost ranges of about $25 € /($ ha yr) are assumed. On the other hand, a larger range is assumed for energy use, i.e. $2.5 \mathrm{GJ} /($ ha yr) which is quite high for short rotation willow production due to harvesting, while the range for GHG emissions is the same as for wheat production.

${ }^{\mathrm{c}}$ For non-intensive management this is equivalent to $60 \%$ of potential yields and for intensive management to $100 \%$ of potential yield (FAO, 2003).

${ }^{d}$ These values are equivalent to $80 \%$ of the potential yield (FAO, 2003).

e Data on wood yields are data from intensive short rotation willow production (Szczukowski et al., 1998). These yields are converted to average agricultural production by the crop yield factor defined in this table.

${ }^{f}$ This refers to a proportion of grain:straw of 1:0.89, which is derived from average cereal straw yields in Poland (CSO, 2003).

electricity are used during the PLA production process and that excess electricity is sold to the grid. This excess electricity is then to substitute electricity produced by European generation capacity.

Data on costs and electric efficiency of grate firing for straw combustion and circulating fluidised beds for lignin combustion are taken from literature. These data refer to stateof-the-art technology (see Table 3). The annual costs of those combustion systems are calculated using investment costs, average O\&M costs as a percentage of investments, an annuity assuming an interest rate of $5 \%$ and a lifetime of 20 years, minus the market revenues of electricity produced and the market value of steam utilised in the PLA production facility. Thus, the costs of bio-energy are the additional costs or profits that result from using bioenergy in the PLA production process instead of using fossil energy. 
Table 3

Input data on steam and electricity production from wheat straw and lignin

\begin{tabular}{lcc}
\hline & $\begin{array}{l}\text { Straw (wheat) } \\
\text { (grate firing) }\end{array}$ & $\begin{array}{c}\text { Lignin (SR wood) } \\
\text { (CFB-combustion) }\end{array}$ \\
\hline Scale (base facility) $\left(\mathrm{TJ}_{\text {input }} / \mathrm{yr}\right)$ & $2880^{\mathrm{a}}$ & $6209^{\mathrm{b}}$ \\
Net electric efficiency $\left(\mathrm{GJ}_{\mathrm{e}} / \mathrm{GJ}_{\text {input }}\right)$ & $0.31^{\mathrm{c}}$ & $0.16^{\mathrm{d}}$ \\
Net steam efficiency $\left(\mathrm{GJ}_{\mathrm{th}} / \mathrm{GJ}_{\text {input }}\right)$ & 0.59 & $0.54^{\mathrm{d}}$ \\
GHG emissions $\left(\mathrm{Mg} \mathrm{CO} \mathrm{Cg}_{\text {biomass }}\right)$ & $0.001^{\mathrm{e}}$ & $0.001^{\mathrm{e}}$ \\
Investment costs $\left(€_{2002} / \mathrm{kW}_{\text {input }}\right)$ & $864^{\mathrm{f}}$ & $641^{\mathrm{g}}$ \\
Annual operational costs $(\mathrm{part}$ of investment) & 0.04 & 0.04 \\
Lower heating value $(\mathrm{GJ} / \mathrm{Mg})$ & $15.6^{\mathrm{h}}$ & 20.1
\end{tabular}

${ }^{a}$ Based on large straw grate firing of $100 \mathrm{MW}_{\text {thinput }}$ as currently used in Denmark (van der Lans et al., 2000). Load factor is assumed to be $7000 \mathrm{~h} / \mathrm{yr}$. Investment costs in the analyses are calculated from this basic scale, by a scale factor of 0.8 and the actual size of the bio-energy facility.

b Based on lignin combustion unit from ethanol production process of $203 \mathrm{MW}_{\text {thinput }}$ (Aden et al., 2002). Load factor is assumed to be $8000 \mathrm{~h} / \mathrm{yr}$. Investment costs in the analyses are calculated from this basic scale, by a scale factor of 0.8 and the actual size of the bio-energy facility.

${ }^{c}$ Calculated from trend line generated from efficiencies of different biomass combustion plants (Dornburg and Faaij, 2001a). For comparison, Kumar et al. (2003) estimate the electric efficiency of a $450 \mathrm{MW}_{\mathrm{e}}$ plant to be $34 \%$, while the approach above results in an efficiency of about 36\%. Net steam efficiency is derived from an average overall thermal efficiency of $90 \%$ (van den Broek et al., 1995).

$\mathrm{d}$ These efficiencies correspond to the NREL design for ethanol production from corn stover with a scale of about $2000 \mathrm{Mg}_{\text {biomaass }}$ /day and efficiencies (HHV) of about 15\% electric and 51\% steam (Aden et al., 2002). For comparison efficiencies (HHV) of black liquor gasification are about $22 \%$ electric and $41 \%$ steam and efficiencies (HHV) of Tomlinson boiler (as used in pulp and paper mills) are about $10 \%$ electric and $52 \%$ steam.

${ }^{\mathrm{e}}$ Biomass is seen as $\mathrm{CO}_{2}$ neutral, because the carbon that is emitted during combustion has been sequestered during plant growth. Emissions for production and transport of biomass are accounted for separately (see Sections 3.1 and 3.6). Indirect emissions of bio-energy plants in general are in the magnitude of $3 \mathrm{~kg} / \mathrm{GJ}_{\mathrm{e}}$ (Mann and Spath, 1997).

${ }^{\mathrm{f}}$ Investment costs for a $100 \mathrm{MW}_{\text {input }}$ plant, based on a scaling factor of 0.8 and investment costs of a $450 \mathrm{MW}_{\mathrm{e}}$ straw combustion plant of 1300 US $\$ 2000 / \mathrm{kW}_{\mathrm{e}}$ (Kumar et al., 2003). These data are based on van den Broek et al. (1995), DOE (1997) and Wiltsee (2000).

$\mathrm{g}$ Investment costs correspond to the NREL design for ethanol production for a boiler of about $203 \mathrm{MW}_{\text {input }}$. Equipment costs for boiler and steam turbine are about 38.3 million US\$2000. To these cost we added project investment costs of the total facility by the share of combustion equipment costs to total equipment costs. To adopt costs to the scale of lignin combustion that corresponds to a PLA production facility of a certain scale, a scale factor of 0.7 is applied (Kreutz et al., 1998).

${ }^{\mathrm{h}}$ LHV as received, i.e. $10 \%$ moisture (ECN, 2003).

\subsection{PLA production}

In principle, PLA production comprises the conversion of biomass to fermentable sugars, fermentation of these sugars to produce lactic acid, purification of lactic acid and its polymerisation. Currently, PLA is produced commercially from starch crops, while it is not produced from ligno-cellulose. Cargill Dow, however, envisages producing PLA from ligno-cellulose in the next 5-8 years, because this process has higher efficiencies (Vink et al., 2003). Therefore, in this study, both processes, i.e. PLA production from starch and from ligno-cellulose are investigated.

Only few process data on PLA production are publicly available. Therefore, input data often had to be estimated on basis of available aggregated data as discussed in detail below. 


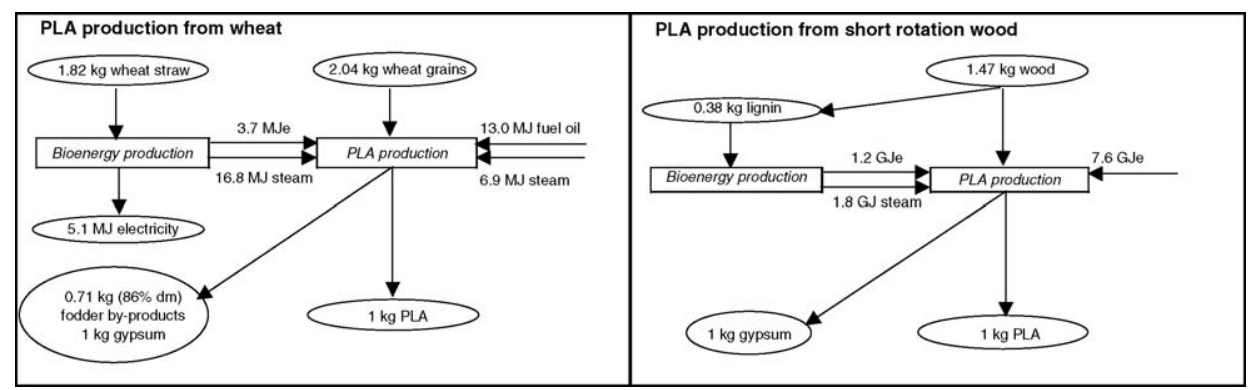

Fig. 6. Overview of main energy and mass flows for PLA production from wheat and short rotation wood.

Input data are shown in Table 4, and the most important mass and energy flows are summarised in Fig. 6.

For PLA production from wheat, data on starch production is taken from an LCA of bio-based polymer production in Germany (Würdinger et al., 2002) and data for sugar production from a summary of LCA data on starch products (AAc, 2001). For the process of PLA production from sugar detailed process data have not been published. For this reason aggregated data from an LCA of Cargill Dows production facility in the U.S. being by far the largest installation with a capacity of $140,000 \mathrm{Mg}_{\mathrm{PLA}} / \mathrm{yr}$ are used (Vink et al., 2003). Moreover, no information on investment costs of a PLA production facility is available, but estimates of production costs. These costs are adjusted to the scale of our facility by a general scaling factor (0.7).

Also for the production of PLA from ligno-cellulose, e.g. from short rotation wood, only limited aggregated process data are available. Based on a confidential NREL study, Cargill Dow expects that the production of PLA from ligno-cellulose will increase the production efficiency significantly (Vink et al., 2003). Therefore, we estimate the performance of this process on basis of publicly available NREL data on ligno-cellulose pre-treatment (Wooley et al., 1999; McAloon et al., 2000) and data on PLA production from ligno-cellulose (Vink et al., 2003). Concerning production costs, projections of Cargill Dow for a ligno-cellulose

Table 4

Input data on PLA production

\begin{tabular}{lcc}
\hline PLA production from & Winter wheat & SR wood \\
\hline Base scale facility $\left(\mathrm{Mg}_{\text {biomass }}\right)$ & $285714^{\mathrm{a}}$ & $323316^{\mathrm{b}}$ \\
Products & & $0.68^{\mathrm{d}}$ \\
PLA (Mg & & $0.49^{\mathrm{c}}$ \\
By-product: gypsum $\left(\mathrm{Mg}_{\text {by-prod }} / \mathrm{Mg}_{\text {biomass }}\right)$ & $0.49^{\mathrm{e}}$ & - \\
By-products: milling $\left(\mathrm{Mg}_{\text {by-prod }} / \mathrm{Mg}_{\text {biomass }}\right)$ & $0.21^{\mathrm{f}}$ & - \\
By-product: gluten meal $\left(\mathrm{Mg}_{\text {by-prod }} / \mathrm{Mg}_{\text {biomass }}\right)$ & $0.09^{\mathrm{f}}$ & - \\
By-product: pulp $\left(\mathrm{Mg}_{\text {by-prod }} / \mathrm{Mg}_{\text {biomass }}\right)$ & $0.50^{\mathrm{f}}$ & $0.26 \mathrm{~g}^{\mathrm{g}}$ \\
By-product: lignin $\left(\mathrm{Mg}_{\text {by-prod }} / \mathrm{Mg}_{\text {biomass }}\right)$ & - & \\
Energy use & & $1.4^{\mathrm{i}}$ \\
Heat use $\left(\mathrm{GJ}_{\text {heat }} / \mathrm{Mg}_{\text {biomass }}\right)$ & $12.9^{\mathrm{h}}$ & $0.00^{\mathrm{i}}$ \\
Fuel use $\left(\mathrm{GJ}_{\text {fuel }} / \mathrm{Mg}_{\text {biomass }}\right)$ & $10.8^{\mathrm{h}}$ &
\end{tabular}


Table 4 (Continued)

\begin{tabular}{lcc}
\hline PLA production from & Winter wheat & SR wood \\
\hline Electricity use $\left(\mathrm{GJ}_{\mathrm{e}} / \mathrm{Mg}_{\text {biomass }}\right)$ & $1.8^{\mathrm{h}}$ & $6.8^{\mathrm{i}}$ \\
Production costs & & \\
$\quad$ Production costs at base scale $\left(€ / \mathrm{M}_{\mathrm{gPLA}}\right)$ & $2310^{\mathrm{a}}$ & $1038^{\mathrm{j}}$ \\
Scale factor production costs & $0.7^{\mathrm{k}}$ & $0.7^{\mathrm{k}}$ \\
\hline
\end{tabular}

a Currently, production cost of PLA are still quite high due to the start-up of the first large scale facility. However, for the near future lower costs are projected. Leaversuch (2002) states 2002 production costs at $1.30 \mathrm{US} \$ / \mathrm{lb}$, while Cargill Dow aims to produce PLA below $1 \mathrm{US} \$ / \mathrm{lb}$ in the near future. We use the latter estimate as basis production costs for a facility of about $140,000 \mathrm{Mg} / \mathrm{yr}$ as the Cargill Dow facility in Nebraska. However, parts of these production costs are feedstock costs for corn that are subtracted from the production costs. Costs of corn (for ethanol production) are about 1.94 US\$ per bushel or 76.4 US\$/Mg (McAloon et al., 2000).

b Cargill Dow envisages to reach a total capacity of 500 million kg PLA per year with three production facilities, two producing PLA from sugar/starch crops and one from ligno-cellulose feedstock (Crank et al., 2004). As the first starch facility has a capacity of 140 million $\mathrm{kg}$ per million $\mathrm{kg}$, we assume that the ligno-cellulose facility is scaled at 220 million $\mathrm{kg}$.

${ }^{c}$ From data given in Vink et al. (2003), it can be concluded that Cargill Dow uses about $1.74 \mathrm{~kg}$ US corn per kg PLA. The amount of wheat has been calculated by average starch contents, i.e. 72\% (McAloon et al., 2000) and $60 \%$ for wheat (Würdinger et al., 2002).

d Wood from short rotation willow contains about $60.5 \%$ cellulose and $29.8 \%$ hemicellulose (ECN, 2003) of which about $80 \%$ or $95 \%$, respectively, can be converted to fermentable sugars by pre-treatment (Wooley et al., 1999). We assume that all of the produced $C_{5}$ and $C_{6}$ sugars can be fermented at the same efficiency then glucose from starch due to technological development in fermentation technology as Cargill Dow envisages an optimised lactic acid production step by then (Vink et al., 2003).

${ }^{\mathrm{e}}$ Few data on gypsum production are available. Garlotta (2001) estimates that up to $1 \mathrm{Mg} / \mathrm{Mg}$ lactic acid can be produced. As no lower range is given in literature, we use this upper range value.

${ }^{\mathrm{f}}$ Würdinger et al. (2002).

g Average lignin content of willow wood is about $26 \%$ (HHV: $\left.21.4 \mathrm{GJ} / \mathrm{Mg}_{\mathrm{dm}}\right)(\mathrm{ECN}, 2003)$.

$\mathrm{h}$ The only information of energy use of PLA production from dextrose is an aggregated total of $39.5 \mathrm{MJ} / \mathrm{kg}_{\text {PLA }}$ (Vink et al., 2003). About $14.9 \mathrm{MJ} / \mathrm{kg}_{\mathrm{PLA}}$ of this total energy amount are used for fuel and electricity in the facility, while the rest is related to operating supplies and waste water treatment. We assume that this rest is fuel use. The largest part of energy use in the facility is steam, because lactic acid is purified with vacuum distillation and steam is used for the heating of the fermentation reactor (Gruber and O'Brien, 2002). We assume that about $95 \%$ of energy use in the facility is steam and the rest is electricity. Moreover, we assume that the data given by Vink et al. (2003) are related to primary energy. We recalculate these data to energy uses by the energy factors stated in this table. Energy use for starch production is $1.65 \mathrm{MJ}$ electricity, $0.005 \mathrm{MJ}$ fuel oil and $7.05 \mathrm{MJ}$ steam per $\mathrm{kg}$ wheat (Würdinger et al., 2002). At the same time biogas is produced in wastewater treatment that is used for steam production. We assume that about $90 \%$ of biogas is converted into steam i.e. $0.55 \mathrm{MJ} / \mathrm{kg}$. Finally, also the energy use for production of liquid sugars from starch is added. Gross energy requirement is about $3 \mathrm{MJ} / \mathrm{kg}$ of sugars (AAc, 2001) or about $1.8 \mathrm{MJ} / \mathrm{kg}$ wheat. This energy demand is assumed to be heat for liquefaction.

i Only very aggregated data on energy use could be found. Using future lactic acid production technology reduces energy use for PLA production about $5.3 \mathrm{MJ} / \mathrm{kg}_{\text {PLA }}$ (Vink et al., 2003) i.e. the energy use for PLA production is $24.2 \mathrm{MJ} / \mathrm{kg}_{\text {PLA }}$ if original energy use is $29.5 \mathrm{MJ} / \mathrm{kg}_{\text {PLA }}$. From the total energy use about $21.8 \mathrm{MJ} / \mathrm{kg}_{\text {PLA }}$ are electricity. In this case we assume that the remaining energy use is equivalent to steam use for the heating of the fermentation reactor and the waste water treatment. Moreover, we assume that the data given by Vink et al. (2003) are related to primary energy and recalculate this to energy uses by the energy factors stated in this table.

${ }^{\mathrm{j}}$ For 2010 Cargill Dow projects production costs of about $1.30 € / \mathrm{kg}_{\mathrm{PLA}}$, i.e. costs competing with PET production costs (Crank et al., 2004). These production cost contain feedstock costs of corn stover. From the composition of corn stover, we can estimate that about $2.15 \mathrm{~kg}$ of stover yield $1 \mathrm{~kg}$ of PLA, while costs of corn stover are about 35 US $\$ / M g$ (McAloon et al., 2000). Production costs are recalculated to current costs of 2003 by an average deflator of $2 \%$.

${ }^{\mathrm{k}}$ Faaij et al. (1998). 
production facility are used (Crank et al., 2004) and scaled by a general scaling factor, too. ${ }^{3}$

\subsection{Substitution of reference products}

As described in Section 2, it is accounted for the fact that main and by-products of the bio-refinery system replace reference products. In this section, reference products of by-products of PLA are discussed. Data on the substitution of by-products, PLA end products and energy carriers are taken from life cycle assessments or similar studies and from market price surveys, see Table 5. For the use of energy in the process (heat, electricity and fuel oil) and for the substitution of non-renewable fuels, data refer to European energy balances.

The extraction of starch from wheat results in by-products from milling, gluten and pulp, whereas during conversion of ligno-cellulose to fermentable sugar lignin arises. Unlike lignin that is combusted for energy production, milling by-products, gluten and pulp are used as fodder. These by-products are assumed to be sold at current market prices and to substitute reference fodder products. Milling by-products are mostly used for cattle fodder. It is assumed that they replace wheat grains, which are closest in nutritional composition. Gluten has a relatively high protein content and can therefore replace other protein-rich fodder products as fishmeal. Finally, pulp from starch production has a relative low nutritional value. It mainly replaces other industrial by-products that are used as pig fodder. Consequently, no energy or GHG emission credits for pulp are taken into account.

Besides milling by-products and lignin, also gypsum is produced as by-product within the PLA production process during the separation of lactic acid by calcium hydroxide or calcium carbonate (Garlotta, 2001). However, for gypsum the same argumentation as for pulp applies, because most gypsum used is a by-product from industrial processes, e.g. from flue gas cleaning, and has a low market value. As a consequence, no credits for substitution or market revenues are taken into account for gypsum.

PLA as the main product of the process is suitable for the production of a broad range of end products, e.g. agricultural plastics, diapers and electric appliances. The largest categories of current use are packaging (70\%) and fibres (3-28\%) (Crank et al., 2004). Cargill Dow expects that in the future these proportions will be about reversed. Therefore, both packaging and fibres are regarded as end products with different shares.

While theoretically many petrochemical polymers can be substituted depending on the specific application, for this study the most likely substitution products (due to market shares and substitution possibilities) are selected. In the case of packaging this is HDPE and in the case of fibres this is PET. Because it is assumed that processing pellets into packaging or fibres is comparable for PLA and petrochemical polymers, PLA is compared to petrochemical polymers on a pellet basis.

\footnotetext{
${ }^{3}$ No factors for technological learning are applied, as the production cost estimates for PLA production from wheat as well as from SR wood are for the next facility to be built. Therefore, technological learning is implicitly included in these estimates.
} 
Table 5

Input data on substitution of reference products and energy

\begin{tabular}{|c|c|c|c|c|c|c|}
\hline $\begin{array}{l}\text { Products and } \\
\text { energy uses of } \\
\text { bio-refinery }\end{array}$ & $\begin{array}{l}\text { Functional } \\
\text { unit }\end{array}$ & $\begin{array}{l}\text { Kind of substitution } \\
\text { product }\end{array}$ & $\begin{array}{l}\text { Primary } \\
\text { energy use } \\
\left(\mathrm{GJ}_{\mathrm{p}}\right) \\
\end{array}$ & $\begin{array}{l}\text { GHG } \\
\text { emissions } \\
\left(\mathrm{kg} \mathrm{CO}_{2 \mathrm{eq}}\right) \\
\end{array}$ & $\begin{array}{l}\text { Agricultural } \\
\text { land demand } \\
\text { (ha) }\end{array}$ & $\begin{array}{l}\text { Market } \\
\text { prices } \\
(€) \\
\end{array}$ \\
\hline Heat & per $\mathrm{GJ}_{\mathrm{th}}$ & Heat mix chem. ind. & $1.35^{\mathrm{a}}$ & $123 \mathrm{GJ}^{-1 \mathrm{a}}$ & 0 & $5.6^{\mathrm{b}}$ \\
\hline Fuel oil & per $G_{\text {fuel }}$ & EU mix oil products & $1.11^{\mathrm{c}}$ & $83^{c}$ & 0 & $\mathrm{n} / \mathrm{a}$ \\
\hline Electricity & per $\mathrm{GJ}_{\mathrm{e}}$ & EU mix electricity & $2.48^{\mathrm{d}}$ & $126^{\mathrm{e}}$ & 0 & 8.9 \\
\hline $\begin{array}{l}\text { Milling } \\
\text { by-products }\end{array}$ & per $\mathrm{Mg}_{\text {by-prod }}$ & Wheat grains & $1.2^{\mathrm{f}}$ & $224^{\mathrm{f}}$ & $0.33^{\mathrm{g}}$ & $83.6^{\mathrm{h}}$ \\
\hline Gluten & per $\mathrm{Mg}_{\text {by-prod }}$ & Fish meal & $0.05^{\mathrm{i}}$ & $2374^{\mathrm{i}}$ & 0 & $971.3^{\mathrm{j}}$ \\
\hline Pulp & per $\mathrm{Mg}_{\text {by-prod }}$ & $\begin{array}{l}\text { Industrial } \\
\text { by-products }\end{array}$ & 0 & 0 & 0 & $4.3^{\mathrm{h}}$ \\
\hline Packaging & per Mg $g_{\text {PLA }}$ & HDPE pellets & $76.6^{\mathrm{k}}$ & $5070^{1}$ & 0 & $902^{\mathrm{m}}$ \\
\hline Fibres & per $\mathrm{Mg}_{\text {PLA }}$ & PET pellets & $77.2^{\mathrm{k}}$ & $5702^{1}$ & 0 & $1726^{\mathrm{n}}$ \\
\hline
\end{tabular}

${ }^{a}$ No data on the European steam production mix are available. Therefore, we use data for the German chemical industry mix. For comparison Polish heavy oil boiler have an efficiency of about 1.57 MJ/MJ (UBA, 2003).

b Average costs of heat production in fossil fuel boilers of 0.02€/kWh in Europe are assumed (EC, 2000).

${ }^{c}$ European Union oil product mix for production. For $\mathrm{CO}_{2}$ emissions we added $74.1 \mathrm{~kg} / \mathrm{GJ} \mathrm{CO}_{2}$ emissions due to carbon content of fuel (UBA, 2003).

${ }^{\mathrm{d}}$ European Union electricity mix (UBA, 2003).

e Data on CHP and electricity production, allocation of $\mathrm{CO}_{2}$ emissions to heat and electricity on an energy basis (IEA, 2002).

${ }^{\mathrm{f}}$ Average nutrition value of milling by-products is about $5.54 \mathrm{MJ} / \mathrm{kg}$, while wheat grains that are substituted have a nutrition value of $8.03 \mathrm{MJ} / \mathrm{kg}$ (Hydro Agri Dülmen GmbH, 1993). Energy use and GHG emissions of wheat production are taken from input data on crop production from this article.

$\mathrm{g}$ Calculated from average grain yield on medium quality land in Poland, see Section 3.1.

$\mathrm{h}$ Würdinger et al. (2002).

${ }^{i}$ Substitution is made on basis of protein content, i.e. 3\% for gluten and 70\% for fish meal (Hydro Agri Dülmen $\mathrm{GmbH}, 1993)$. Energy use of fish meal production is derived from Carlsson-Kanyama and Faist (2000) and GHG emission factors of the European energy mix are applied.

j Average European production costs of $0.032 € / \mathrm{kWh}$ (EC, 2000).

${ }^{\mathrm{k}}$ It is assumed that PLA substitutes HDPE and PET on a 1:1 weight basis. Thus, the values given are values per Mg HDPE and PET, respectively. The energy use of HDPE production is between energy use of LLDPE and LDPE production (APME, 2003a).

${ }^{1}$ Emissions consists of emissions during production and emissions during incineration. For HDPE these are 1928 and $3142 \mathrm{~kg} \mathrm{CO}_{2 \mathrm{eq}}$, respectively and for PET 3410 and $2291 \mathrm{~kg} \mathrm{CO}_{2 \mathrm{eq}}$. Data on emissions during production are derived from UBA (2003) and data on incineration calculated from carbon content of polymers, i.e. $62.5 \%$ for PET and $85.7 \%$ for HDPE; LHV of HDPE is $43.3 \mathrm{GJ} / \mathrm{Mg}$ and for PET 22.1 GJ/Mg (Patel et al., 2002).

${ }^{m}$ PE price (Leaversuch, 2002).

${ }^{\mathrm{n}}$ PET price (Clarinval, 2002).

\subsection{Recycling and waste treatment}

In this study, part of the PLA waste is assumed to be recycled, while the rest is treated by either incineration or digestion. As recycling technology, back-to-monomer (BTM) recycling of PLA is selected, because it is discussed as most promising recycling strategy for PLA (see Gruber and O'Brien, 2002). Energy recovery from PLA waste is covered in the waste treatment part by waste incineration with electricity recovery. However, for back-tomonomer recycling relatively pure PLA waste is necessary that can be obtained by separate 
collection and upgrading processes. While such collection and upgrading structures for municipal solid waste are installed for plastic types with a very large market share, such systems are too costly for plastics with a low market share. Consequently, it is assumed that such a waste collection structure does not come into place in the medium term for PLA. Therefore, only industrial waste, i.e. waste that results from processing of PLA and waste that arise at the commerce level, is assumed to be recycled.

However, BTM recycling of PLA is still in a laboratory stage and only few experiments have been undertaken (e.g. Fan et al., 2003; Tsuji et al., 2003). PLA is converted into L-LA by a short hydrolysis at low temperatures, i.e. about $90 \% \mathrm{LA}$ can be recovered at $250{ }^{\circ} \mathrm{C}$ in 10-20 min (Tsuji et al., 2003). The L-LA is then polymerised to PLA again. However, no process data on energy uses, GHG emissions and costs are available on BTM recycling and we had to estimate these data on basis of chemical properties and knowledge of other recycling processes (see Table 6).

In this study, two different waste treatment technologies for PLA are alternatively investigated. These are digestion and incineration with energy recovery. Digestion makes use of the biodegradable properties of PLA and recovers part of the energy contained in the polymer, while incineration on its part has the potential to reclaim a large amount of energy. Even though digestion can be selected as preferred waste treatment technology for PLA, its maximum share depends on the collection and separation rates of organic wastes and is therefore limited. The remaining waste is incinerated with energy recovery.

For waste treatment performance, data from literature on state-of-the-art technologies in Europe are used, because PLA as well as petrochemical reference polymers will be treated there. Moreover, the Polish government envisages in its environmental policy the compliance of waste management with EU standards in the future (DHV, 2001). Concerning residues of digestion, no credits are taken into account, because PLA ideally degrades completely to water and gases. All input data on recycling and waste treatment technologies are shown in Table 6.

\subsection{Transport}

Transport operations in the PLA bio-refinery system that are different from transports needed to produce and discard reference products are:

- the transport of biomass to the PLA production facility;

- the transport of PLA waste to the recycling facility;

- the possible difference between the transportation of reference plastics to a waste incineration plant and the transportation of PLA to a digestion unit.

Transportation distances are estimated using the radius of a circle in which the material is distributed. In case of biomass production, this is a circle of agricultural land around the around the facility (about $8-30 \%{ }^{4}$ ). For recycling the per capita consumption of plastics, for example about $4.4 \mathrm{Mg} / \mathrm{km}^{2}$ for packaging (APME, 2003b), defines this area resulting in distances of about $180 \mathrm{~km}$ for recycling at the base scale of a PLA facility 285 million

${ }^{4}$ About $8-30 \%$ of the available agricultural land is used for biomass production. This depends on the crop yields, which in turn depend on the land quality used; see Section 3.1. 
Table 6

Input data on recycling and waste treatment, i.e. digestion and incineration with energy recovery

\begin{tabular}{lccc}
\hline & BTM recycling & Digestion $^{\mathrm{a}}$ & Incineration \\
\hline Share of separate collection $\left(\mathrm{Mg}_{\mathrm{PLA}} / \mathrm{Mg}_{\mathrm{PLA}}\right)$ & $0.07 / 0.2^{\mathrm{b}}$ & $0.3^{\mathrm{c}}$ & - \\
GHG emissions $\left(\mathrm{kg} \mathrm{CO}_{2 \mathrm{eq}} / \mathrm{Mg}_{\text {PLA }}\right)$ & $74^{\mathrm{d}}$ & $37.4^{\mathrm{e}}$ & 0 \\
Energy use $\left(\mathrm{GJ} \mathrm{Mgg}_{\mathrm{PLA}}\right)$ & $0.6^{\mathrm{f}}$ & 0.87 & - \\
Electricity production $\left(\mathrm{GJ}_{\mathrm{e}} / \mathrm{Mg}_{\text {PLA }}\right)$ & - & 0.525 & $5.37^{\mathrm{g}}$ \\
Treatment costs $\left(€ / \mathrm{Mg}_{\text {PLA }}\right)$ & $190^{\mathrm{h}}$ & $33.5^{\mathrm{i}}$ & $80^{\mathrm{j}}$ \\
PLA production efficiency $(\mathrm{Mg} / \mathrm{Mg}$ & - & - \\
\hline
\end{tabular}

${ }^{\text {a }}$ State-of-the-art digestion plant (AOO, 2002). All values refer to medium composition of municipal organic waste.

${ }^{\mathrm{b}}$ First value defines average collection rate and second value the maximum collection rates. It is assumed that only industrial waste can be recycled. Possible recycling rates are estimated by averages of European plastic recycling. About $21 \%$ of total plastic wastes in Europe arise in the industry and distribution sector, from which currently about $34 \%$ are recycled without energy recovery (APME, 2003b). Thus, we assume a maximum recycling rate of $20 \%$ of all PLA products and a standard recycling rate of $7 \%$.

${ }^{c}$ In The Netherlands, the objective for separate organic waste collection is about 55\%, while 53\% were realised. Because Poland is less urban, and less experience has been gained we assume a maximum collection rates of $30 \%$. The share of incineration is the share of PLA waste that is not composted or digested.

${ }^{d}$ We assume that $\mathrm{CO}_{2}$ emissions are related only to energy, because no special materials are used for the recycling process. Emissions are calculated with the carbon factor for steam, see Section 3.3.

e GHG emission for a digestion installation with air cleaning by biofilter are $1.1 \mathrm{~kg} \mathrm{CH}_{4} / \mathrm{Mg}_{\text {waste }}$ and $0.046 \mathrm{~kg} \mathrm{~N}_{2} \mathrm{O} / \mathrm{Mg}_{\text {waste }}$ (AOO, 2002). Carbon that is sequestered during biomass production is assumed to be released during biodegradation and during the use of the residue for soil amelioration.

${ }^{\mathrm{f}}$ We assume that for hydrolysis of PLA steam is used for heating, melting and depolymerisation and that efficiency of primary energy use for these steps is about $80 \%$. Specific heat capacity is of most substances is around $1 \mathrm{~kJ} /(\mathrm{kg} \mathrm{K})$, we assume this to be valid for PLA, too. Moreover, polymerisation energy of PLA is $27.0 \mathrm{~kJ} / \mathrm{mol}$ (Brandrup et al., 1999), while general purpose PLA of Cargill Dow has $168 \mathrm{~kg} / \mathrm{mol}$ (Garlotta, 2001). The melt enthalpy of PLA is $93 \mathrm{~kJ} / \mathrm{kg}$ (Södergård and Stolt, 2002).

$\mathrm{g}$ Electric efficiency of a state-of-the-art waste incineration plant complying with EU standards of 30\% (Dornburg and Faaij, 2001b). Electricity production calculated with a lower heating value of PLA, i.e. 17.9 GJ/Mg (Patel et al., 2002).

${ }^{\mathrm{h}}$ No cost estimates are available on this recycling process are available. We therefore assumed current average costs of mechanical and feedstock recycling of plastics, which are about $190 € / \mathrm{Mg}$ (Eggels et al., 2001).

${ }^{\mathrm{i}}$ These are average costs for waste treatment facilities in The Netherlands. Costs depend among others on scale and technology (AOO, 2002).

${ }^{j}$ Investment costs for $235 \mathrm{MW}_{\text {th }}$ installation are about 2.26 million $€_{2000}$ (Zeevalkink and van Ree, 2000). If $50 \%$ of the Polish municipal solid waste would be incinerated in two facilities, scale of the facilities would be $700 \mathrm{MW}_{\text {th }}$. Assuming a scale factor of 0.7 , operation and maintenance costs of $4 \%$ of investment, a life time of 20 years, $5 \%$ interest rate and an average lower heating value of waste of $10 \mathrm{GJ} / \mathrm{Mg}$ results in treatment costs of $80 €_{2002} / \mathrm{Mg}_{\text {waste }}$ without including sales of electricity. For comparison in The Netherlands treatment costs for waste incineration are average about $100 \mathrm{Mg}_{\text {waste }}$ ( $\mathrm{AOO}, 2002$ ).

${ }^{\mathrm{k}}$ Short hydrolysis of PLA at low temperatures leads to highest yields of L-lactic acid, while at different temperatures racemisation occurs which negatively influences the quality of PLA (Fan et al., 2003). About 90\% L-lactic acid can be recovered by hydrolysis at $250^{\circ} \mathrm{C}$ and a processing time of $10-20 \mathrm{~min}$ (Tsuji et al., 2003).

kg biomass input. Finally, for waste treatment we assume that Poland will in short term install more incineration and digestion facilities to comply with EU legislation and resulting average transportation distances of $230 \mathrm{~km}$ for digestion and $140 \mathrm{~km}$ for waste incineration. The means of transportation are assumed to be waste collection vehicles, trucks for distances up to $200 \mathrm{~km}$ and trains for exceeding distances. Data on energy use, GHG emissions and 
Table 7

Input data on transportation of biomass and PLA

\begin{tabular}{llllll}
\hline Parameter & $\begin{array}{l}\text { Truck } \\
\text { transport } \\
\left(\mathrm{Mg}^{-1} \mathrm{~km}^{-1}\right)\end{array}$ & $\begin{array}{l}\text { Truck } \\
\text { transfer } \\
\left(\mathrm{Mg}^{-1}\right)\end{array}$ & $\begin{array}{l}\text { Train transport } \\
\left(\mathrm{Mg}^{-1} \mathrm{~km}^{-1}\right)\end{array}$ & $\begin{array}{l}\text { Train } \\
\text { transfer } \\
\left(\mathrm{Mg}^{-1}\right)\end{array}$ & $\begin{array}{l}\text { Waste } \\
\text { collection } \\
\left(\mathrm{Mg}^{-1} \mathrm{~km}^{-1}\right)\end{array}$ \\
\hline $\begin{array}{l}\text { Energy use }\left(\mathrm{GJ}_{\mathrm{p}}\right) \\
\begin{array}{l}\mathrm{GHG} \text { emissions } \\
\left(\mathrm{kg} \mathrm{CO} \mathrm{CO}_{2 \mathrm{q}}\right)\end{array}\end{array}$ & $0.00125^{\mathrm{a}}$ & $0.005^{\mathrm{b}}$ & $0.00058^{\mathrm{a}}$ & $0.01^{\mathrm{c}}$ & $0.0075^{\mathrm{d}}$ \\
\begin{tabular}{l} 
Costs $(€)$ \\
\hline
\end{tabular} & $0.096^{\mathrm{a}}$ & $0.48^{\mathrm{e}}$ & $0.039^{\mathrm{a}}$ & $0.96^{\mathrm{e}}$ & $0.71^{\mathrm{e}}$ \\
\hline
\end{tabular}

${ }^{a}$ Includes indirect emissions and energy uses, data refer to electric trains in Germany, and an empty return.

b Average truck load transfer data (Suurs, 2002).

c Average train load transfer data (Suurs, 2002).

${ }^{d}$ Data refers to waste collection in The Netherlands with a distance of about $20 \mathrm{~km}$ (VVAV, 1994).

${ }^{\text {e }}$ Calculated from energy use with a direct emission factor of $74 \mathrm{~kg} \mathrm{CO}_{2 \mathrm{eq}} / \mathrm{GJ}$ and $21 \mathrm{~kg} \mathrm{CO}_{2 \mathrm{eq}} / \mathrm{GJ}$ of indirect emissions.

${ }^{\mathrm{f}}$ Costs refer to the situation in The Netherlands and have been derived from Suurs (2002) assuming a load of $120 \mathrm{~m}^{3}$.

g Transportation costs by train differ considerably with different loads and distances. Costs refer to an average distance of $200 \mathrm{~km}$, while in general costs per $\mathrm{t} \mathrm{km}$ are $(16.9 € / \mathrm{ton}+0.0275 € /(\mathrm{t} \mathrm{km})$ distance in $\mathrm{km}) /$ distance in km (Hamelinck, 2004).

costs of transport are state-of-the-art data from a European context. They are presented in Table 7.

\subsection{Demand curves}

In this section, demand curves for the market analysis are presented. These demand curves are determined by own-price elasticity and estimates of current market prices and quantities, see Section 2.2. Reviews of own-price elasticity in different sectors and for different regions show a range of values. Ciaian et al. (2002) found values in economic literature that range from -0.045 to -1.49 for the agricultural sector of different countries. Franssen (1999) reports own-price elasticity of about 0 to -0.3 for energy commodities and transportation fuels in economic literature. Gielen et al. (2000) argue that most own-price elasticity of energy and materials from biomass are between -0.1 and -0.5 .

The value of own-price elasticity can have a large impact on calculated market prices if the production capacity is increased significantly. For example, if the total production capacity is increased by $1 \%$ an elasticity of -0.1 leads to a $10 \%$ decrease of the market price, while an elasticity of -0.5 will result in a $2 \%$ decrease of the market price. Consequently, the selection of appropriate own-price elasticity is crucial for the quantitative results of the market analysis. In this study, demand curves and subsequently own-price elasticity are applied to fodder by-products of PLA from wheat, to agricultural land and to PLA.

Agricultural land and fodder products are commodities in the agricultural sector. Moreover, both commodities can be assumed to be limited to the Polish market. Ciaian et al. (2002) derived an own-price elasticity of -0.24 for the Polish agricultural sector from a 
Table 8

Basic input data used for composing demand curves

\begin{tabular}{|c|c|c|}
\hline Commodity & Market price & Production capacity \\
\hline Low quality agricultural land & $27 €_{2002} /$ (hayr) (rent) & 4.1 million $\mathrm{ha} / \mathrm{yr}^{\mathrm{a}}$ \\
\hline Medium quality agricultural land & $33 €_{2002} /$ (ha yr) (rent) & 8.5 million $\mathrm{ha} / \mathrm{yr}^{\mathrm{a}}$ \\
\hline High quality agricultural land & $39 €_{2002} /($ ha yr) (rent) & 2.7 million $\mathrm{ha} / \mathrm{yr}^{\mathrm{a}}$ \\
\hline By-product: milling & $84 €_{2002} / \mathrm{Mg}$ & 405.2 million $\mathrm{kg} / \mathrm{yr}^{\mathrm{b}}$ \\
\hline By-product: pulp & $971 €_{2002} / \mathrm{Mg}$ & 173.7 million $\mathrm{kg} / \mathrm{yr}^{\mathrm{b}}$ \\
\hline By-product: gluten & $4 €_{2002} / \mathrm{Mg}$ & 964.77 million $\mathrm{kg} / \mathrm{yr}^{\mathrm{b}}$ \\
\hline PLA & $3000 €_{2002} / \mathrm{Mg}^{\mathrm{c}}$ & 143.5 million $\mathrm{kg} / \mathrm{yr}^{\mathrm{d}}$ \\
\hline
\end{tabular}

a This is the total amount of available agricultural land, see Table 1.

b The amount of by-products currently produced is estimated by the amount of wheat flour produced in Poland, i.e. 1.5 million $\mathrm{Mg} / \mathrm{yr}$ in 2000 (UN, 2002) which is equivalent to 1.9 million Mg/yr wheat processed (Würdinger et al., 2002).

c Crank et al. (2004).

d Installed global capacity 2003 (Crank et al., 2004). However, mid-2004 probably about 193,500 Mg/yr capacity of PLA production will be installed and the production capacity investigated in this study has to been seen as additional to that. For comparison the global production of PET fibres is about 910 million kg/yr (CIRFS, 2002). Moreover, the average price of $3.0 € / \mathrm{kg}$ for sales of Cargill Dow is assumed as current market price, while market prices of PLA range from 2.2 to $3.4 \mathrm{~kg}$ (Crank et al., 2004).

partial equilibrium model. This value is used in our analysis for fodder by-products and agricultural land.

Unfortunately, in the case of PLA, no specific estimates of the own-price elasticity are available. PLA is bio-based polymer that replaces petrochemical polymers in a European or even global market. In a study on European (biomass) material and energy use, a generic marginal elasticity of -0.5 for all kind of materials and energy carriers is assumed (Gielen et al., 2000). An analysis of historical prices and volumes of polypropylene and polyethylene from 1970 to 2000 (Crank et al., 2004) results in own-price elasticity of -0.5 and -0.9 , respectively. However, for a generic estimate of elasticity without econometric data, an own-price elasticity of -0.2 to -0.3 might be more realistic (Vöhringer, 2004).

On the other hand, PLA producers and potential producers estimate market prices and production capacities in 2010 (Crank et al., 2004). If all changes in these market price estimations would be due to own-price elasticity, an average value of -2.5 would result. ${ }^{5}$ Note, that this value seems very optimistic, as the producers have assumed only a very small decrease of market price with growing production capacity due to an expected development of large new markets for PLA. In this study, the rather broad range of -0.2 to -2.5 is used for the market analysis of the bio-refinery system to show the broad range of uncertainty with an average value of -0.5 .

Finally, elasticity factors are converted to market prices by using the current market prices and production capacity of agricultural land area as calibration point; see Section 2. These data are summarised in Table 8.

\footnotetext{
5 This value has been calculated by fitting Eq. (1) to the current market volumes and prices and the projected future market prices and volumes.
} 


\section{Results}

\subsection{Performance of the PLA bio-refinery system}

The options of PLA bio-refinery systems that are investigated vary with regard to the crop used for PLA production, the intensity of crop production, the quality of land used, the share of PLA fibre production, the recycling rate and the kind of waste treatment. The various combinations are summarised in Table 9. Scale of the PLA production facility is set at $285,000 \mathrm{Mg}$ biomass input per year, which is equivalent to the scale of the current Cargill Dow production facility for PLA from corn, i.e. 140,000 $\mathrm{Mg}_{\mathrm{PLA}} / \mathrm{yr}$ (Vink et al., 2003).

In Fig. 7, the performance of these options of a PLA bio-refinery system is shown. Savings of non-renewable energy consumption, GHG emission reductions and costs are given per $\mathrm{kg}$ of PLA produced (A-C) and per ha of land used to produce the biomass feedstock (D-F). In general, the results per $\mathrm{kg}$ of PLA and per ha of biomass do not differ substantially except for the options regarding different crop production systems. The intensive systems result in about 40-50\% higher savings of non-renewable energy consumption and GHG emission reductions per ha than the respective base cases. Ranges of savings of non-renewable energy consumption are between 70 and $220 \mathrm{GJ} /$ (ha yr) and ranges of GHG emission reductions are between 3 and $17 \mathrm{MgCO}_{2 \mathrm{eq}}$ /(ha yr). Hence, all options of PLA bio-refinery systems considered result in net energy savings and net GHG emission reduction, but most options result in net costs of the overall bio-refinery system of up to $4600 € /$ (ha yr). Only two

Table 9

Options for PLA bio-refinery systems studied in this analysis

\begin{tabular}{|c|c|c|c|c|c|c|}
\hline Name & Crop & $\begin{array}{l}\text { Crop } \\
\text { production }\end{array}$ & Land use $^{\mathrm{a}}$ & End prod ${ }^{b}$ & Recycling $^{c}$ & $\begin{array}{l}\text { Waste } \\
\text { treatment }\end{array}$ \\
\hline Base case $w$ & Wheat & Normal & $\mathrm{L}, \mathrm{M}, \mathrm{H}$ & 0.7 packaging & Medium & Digestion \\
\hline Intensive crop prod $\mathrm{w}$ & Wheat & Intensive & $\mathrm{M}, \mathrm{H}$ & 0.7 packaging & Medium & Digestion \\
\hline Non-intensive crop prod w & Wheat & Non-intensive & $\mathrm{L}, \mathrm{M}$ & 0.7 packaging & Medium & Digestion \\
\hline End prod fibres w & Wheat & Normal & $\mathrm{L}, \mathrm{M}, \mathrm{H}$ & 0.2 packaging & Medium & Digestion \\
\hline Recycling high w & Wheat & Normal & $\mathrm{L}, \mathrm{M}, \mathrm{H}$ & 0.7 packaging & Maximum & Digestion \\
\hline Waste incineration w & Wheat & Normal & $\mathrm{L}, \mathrm{M}, \mathrm{H}$ & 0.7 packaging & Medium & Incinerate \\
\hline Base case SRC & $\mathrm{SRC}^{\mathrm{d}}$ & Normal & $\mathrm{L}, \mathrm{M}, \mathrm{H}$ & 0.7 packaging & Medium & Digestion \\
\hline Intensive crop prod SRC & SRC & Intensive & $\mathrm{M}, \mathrm{H}$ & 0.7 packaging & Medium & Digestion \\
\hline $\begin{array}{l}\text { Non-intensive crop prod } \\
\text { SRC }\end{array}$ & $\mathrm{SRC}$ & Non-intensive & $\mathrm{L}, \mathrm{M}$ & 0.7 packaging & Medium & Digestion \\
\hline End prod fibres SRC & SRC & Normal & $\mathrm{L}, \mathrm{M}, \mathrm{H}$ & 0.2 packaging & Medium & Digestion \\
\hline Recycling high SRC & SRC & Normal & $\mathrm{L}, \mathrm{M}, \mathrm{H}$ & 0.7 packaging & Maximum & Digestion \\
\hline Waste incineration SRC & SRC & Normal & $\mathrm{L}, \mathrm{M}, \mathrm{H}$ & 0.7 packaging & Medium & Incinerate \\
\hline
\end{tabular}

${ }^{a}$ L: low quality land, M: medium quality land, H: high quality land; In the base case all types of land are used for biomass production, while in the intensive crop production scenario only high and medium quality land is used, and in the extensive crop production scenario only low and medium quality land is used.

b These shares refers to current (70\%) and potential future market shares (20\%) for packaging as estimated by Cargill Dow (Crank et al., 2004). It is assumed that all the rest is used for fibre production.

${ }^{c}$ Medium recycling refers to an overall recycling rate of $7 \%$, while maximum refers to a recycling rate of $20 \%$ (see Section 4).

${ }^{\mathrm{d}}$ Short rotation coppice, i.e. PLA production from short rotation wood. 

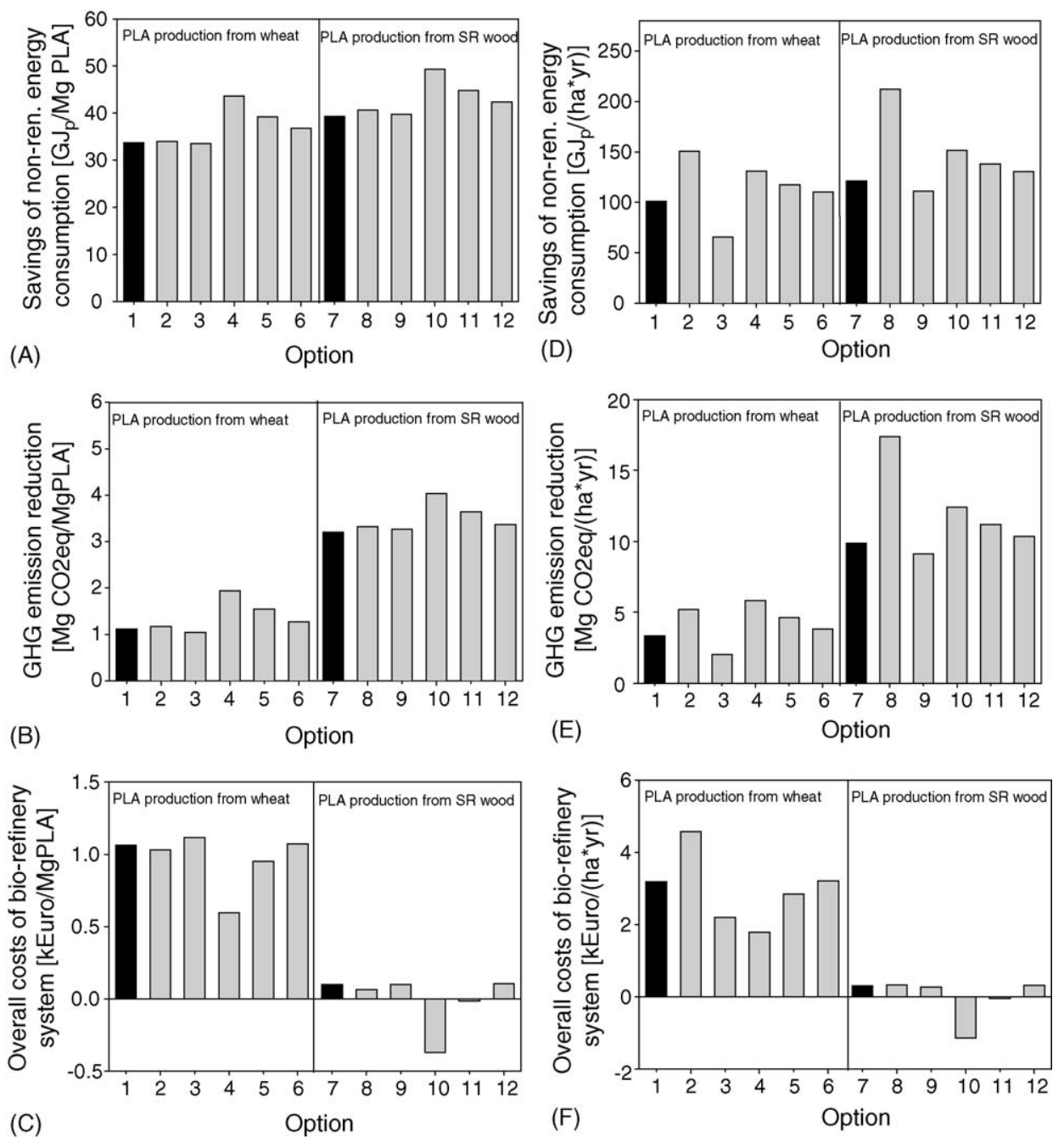

1,7: Base case; 2.8: Intense crop PLA productionf from wheat; 7-12:PLA production from SR wood

Fig. 7. Savings of non-renewable energy consumption (A and D), GHG emission reductions (B and E) and costs ( $\mathrm{C}$ and F) of 'multi-functional' PLA production systems relative to the reference system. For a detailed explanation of options see Table 9.

options of short rotation wood studied lead to net profits of about 50 and $1100 € /$ (ha yr), respectively. These are the options with a high share of recycling (no. 11) and with a high share of PLA fibre production (no. 10). This is due to the fact that production costs of PLA from wood are low compared to wheat and that market prices of PET for which the fibres are sold are relatively high.

From the comparison of the different options among each other, conclusions which system elements have the largest (positive) impact on the overall performance can be drawn. 
If we compare PLA production from wheat (nos. 1-6) with PLA production from short rotation wood, it can be concluded that with regard to savings of non-renewable energy consumption and GHG emission reductions, the latter is favourable. The PLA bio-refinery system using wood has about $25 \%$ higher savings of non-renewable energy consumption than the PLA bio-refinery system using wheat and about the double GHG emission reductions in the base case. From a cost point of view, PLA production from short rotation wood is much more favourable than PLA production from wheat.

Comparing biomass production systems, intensive crop production (nos. $2+8$ ) on high quality lands is most favourable with regard to non-renewable energy consumption and GHG emission reductions. In contrast, non-intensive crop production (nos. $3+9$ ) on low quality lands is favourable with respect to costs on a per ha basis but not on a per $\mathrm{kg}$ of PLA basis. The production of more fibres instead of packaging materials (nos. $4+10)$ and the application of a higher recycling rate (nos. $5+11$ ) have a positive effect on savings of non-renewable energy consumption, GHG emissions and costs and exceed the base case by about $10-50 \%$. Finally, waste incineration (nos. $6+12$ ) instead of partly digestion of PLA waste (nos. $1+7$ ) leads to slightly higher savings of non-renewable energy consumption and GHG emission reductions, but also to marginally higher costs of the bio-refinery system.

Fig. 8 presents the breakdown of the results presented in Fig. 7. In other words, it shows non-renewable energy consumption and savings, GHG emissions and reductions, and costs and profits per $\mathrm{kg}$ of biomass input for every main step of the process chain considered. The energy and GHG emission balances are similar in the distribution of savings over the main components and are, therefore, discussed together. The substitution of petrochemicals, the production of PLA and bio-energy production are the most important components in the energy and GHG emission balances. The energy production potential and resulting GHG emission reductions of biomass residues are quite large and nearly completely compensate for the energy use during PLA production from wheat (nos. 1-6). For PLA production from short rotation wood (nos. 7-12), energy uses and GHG emissions are much lower due to a more efficient production process, but also the benefits from bio-energy production are much lower as less residues become available for direct energy production. Crop production accounts only for a small part of energy use and for a slightly larger part to GHG emissions, due to $\mathrm{N}_{2} \mathrm{O}$ emissions resulting from fertilizer use. Recycling and waste treatment of PLA contribute for a smaller part to the energy savings and GHG emission reductions of the bio-refinery systems. Finally, substitution effects of by-products only play a very small role in the total energy and GHG emission balances, while transport is not significant at all with a share of less than $1 \%$.

The breakdown of costs of the PLA bio-refinery systems reveals that PLA production represents the largest share of costs. On the other hand, the profits from the substitution of petrochemical polymers, i.e. the revenues from PLA sales, are the largest part of the revenues, too. PLA production costs from short rotation wood are lower than from wheat and moreover, revenues from PLA sales are higher due to a more efficient production process. If a higher share of fibres is produced from the biomass input, higher revenues from PLA sales are achieved. Revenues of by-products, which arise in the wheat production options, are more significant in the overall cost balance than their contribution to energy savings or GHG emission reductions, while recycling and waste treatment have comparatively less important revenues. Bio-energy production does not contribute significantly to revenues in 

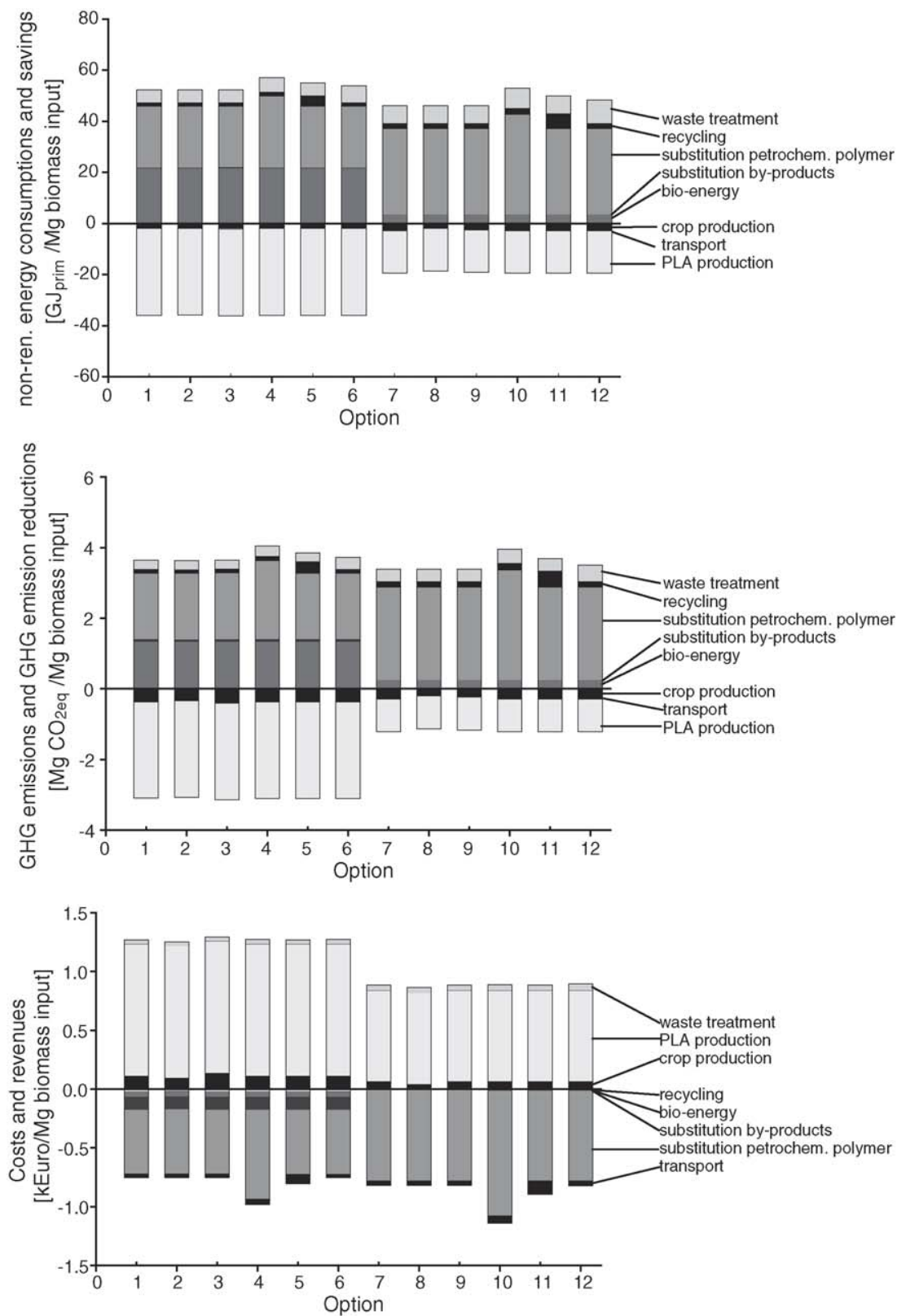

1-6: PLA productionf from wheat; 7-12:PLA production from SR wood

1,7: Base case; 2,8: Intense crop production; 3,9: Non-intensive crop production;

4,10: Fibre production 5,11: High recycling; 6,12: Waste incineration

Fig. 8. Breakdown of energy and greenhouse gas balances and costs structures of multi-functional PLA production systems per kg of biomass input. For a detailed explanation of options see Table 9. 

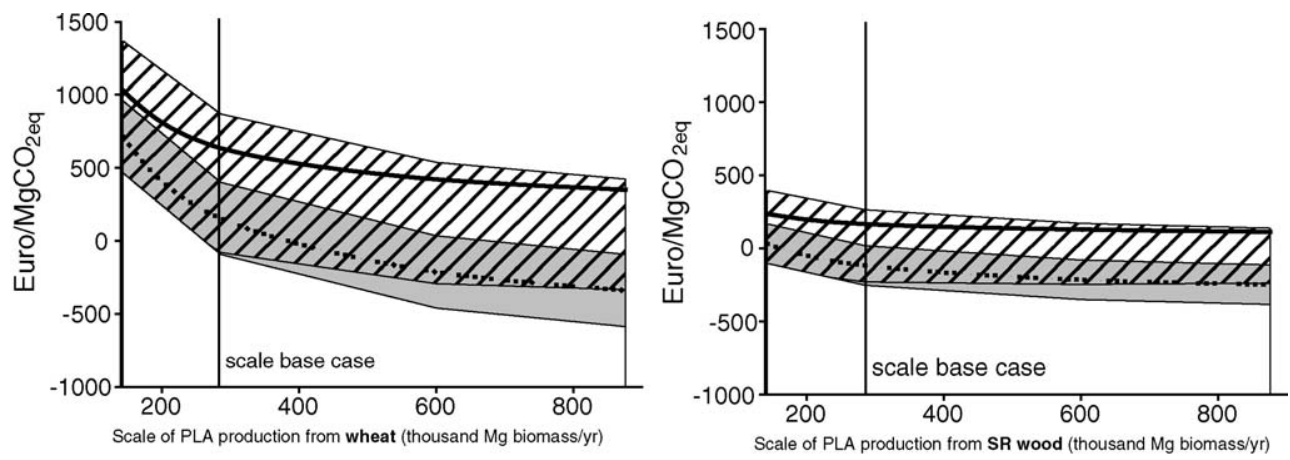

$$
\begin{aligned}
& \text { range due to range of own-price elasticity }(-0.2 \text { to }-2.5) \\
& \text { range due to historical range of market prices of petrochemical polymers } \\
& \text { mitgation costs of bio-refinery system calculated with demand curve of PLA (elasticity }-0.5) \\
& \text { mitigation costs of bio-refinery system calculated with market prices of petrochemical polymers }
\end{aligned}
$$

Fig. 9. Costs (positive) or income (negative) per $\mathrm{Mg}$ of avoided $\mathrm{CO}_{2}$ equivalent emissions in relation to the market supply of a PLA production facility.

contrast to its contribution to the energy savings and GHG emission reductions. Finally, also in the cost balance, crop production accounts only for a small part and transportation is not significant.

\subsection{Costs in relation to scale}

In this section, costs per Mg of GHG emission reduction as achieved by PLA bio-refinery systems are investigated in relation to the production scale of PLA. For this analysis, the best PLA bio-refinery systems from wheat and from short rotation wood with respect to costs per $\mathrm{Mg}$ of avoided $\mathrm{CO}_{2}$ equivalent from the previous analysis are considered. These PLA bio-refinery systems use intensive crop production, produce about $70 \%$ of fibres, have a maximum share of recycling and incinerate the PLA waste.

In Fig. 9, the dotted line shows the relation between costs and the production capacity of the PLA plant due to logistics and economies of scale. The solid line depicts this relation also taking into account the own-price elasticity of the demand for materials and agricultural land. If scale effects are regarded without considering market price changes due to the larger production capacity (dotted line), GHG emission mitigation costs decrease with scale and become profitable at around $200 \mathrm{Mg}$ biomass input per year for SR wood and $400 \mathrm{Mg}$ biomass input per year for wheat. However, if market elasticity is taken into account (solid line), costs decrease less with increasing scale. At the larger scales regarded in this analysis, the decrease of costs becomes marginal and GHG emission mitigation costs are constant with scale. This effect is explained mainly by the gradually decreasing market price of PLA with larger scales.

It should be noted that costs at the 'base' scale, i.e. $140,000 \mathrm{Mg}_{\mathrm{PLA}} / \mathrm{yr}$, which is the scale of analysis in Section 4.1, are higher in the analysis with own-price elasticity than in the analysis without own-price elasticity. In the analysis without own-price elasticity, the market price of PLA is equivalent to the market price of its petrochemi- 
cal reference polymers, while the market price of PLA is lower with the demand curve used.

Fig. 9 also shows the ranges of the GHG emission mitigation cost estimates. For the costs that are calculated taking into account elasticity, these ranges correspond to the ranges of own-price elasticity for PLA; see Section 3.7. For mitigation costs that are calculated without elasticity (dark grey), ranges correspond to historical price changes of petrochemical polymers. Historical changes of prices were due to many factors like the price of competing materials, income developments, but also the own-price elasticity of demand. Ranges used in this analysis are based on prices of ethylene that is an important intermediate for both HDPE and PET. These prices varied from 1995 to 2002 about $\pm 35 \%$ (Cefic, 2003). It is obvious that the own-price elasticity of PLA and the market prices of petrochemical reference materials influence the (subsequently) calculated GHG mitigation costs, significantly.

As discussed above, market price changes of PLA play an important role in the market analysis of the bio-refinery system using own-price elasticity. On the other hand, market price changes of land and by-products are much less important, because crop production costs and by-product revenues are quite small compared to PLA revenues. Nevertheless, land rents increase up to about $6 \%$ and by-product revenues even decrease up to $80 \%$ for a PLA bio-refinery system with $900,000 \mathrm{Mg}$ biomass input per year.

\section{Discussion}

In this study, GHG emission reductions, primary energy savings and costs of PLA biorefinery systems in different configurations have been presented. Even though our analysis provides a good insight into the mechanisms relevant for bio-refinery systems and into the possible ranges of benefits, uncertainties due to the quality of input data remain. In principle, data on crop production, bio-energy conversion, petrochemical polymer production and waste treatment are relatively well known. Less well known are the specifications of PLA production and recycling.

The current technology to produce PLA from starch is at large scale only used in a single plant since 2001, while the technology produce PLA from ligno-cellulose is not employed on a large scale, yet. Therefore, few process data exist. Variations in these data, however, can have a significant impact on the overall results, because PLA production is one of the largest components in the balances of energy, GHG emissions and also costs. In general, the total energy savings are quite sensitive to the energy use of PLA production; an increase of $10 \%$ leads to a relative decrease of savings of non-renewable energy consumption of $5 \%$ for short rotation wood and $20 \%$ for wheat.

In addition, also for PLA production costs only estimations of total costs are available without any specifications, e.g. investments costs. In order to evaluate economies of scale, production costs are calculated with a scaling factor, although some cost factors are to a smaller degree subject to economies of scale, e.g. process inputs or reactors above a certain size. As a consequence, economies of scale of the PLA plant tend to be overestimated in this analysis. Another important aspect concerning PLA production costs is, that manufacturers in such a small market may not reveal their real costs to their competitors creating uncer- 
tainties in cost assessments. Total costs of the bio-refinery system would increase about $25-30 \%$, if production costs were $10 \%$ higher than estimated in this study.

BTM recycling is still in the laboratory stage and no process data exist resulting in poor data availability. However, recycling does not play a large role in the calculation of overall energy savings, GHG emission reductions and costs as only small parts of PLA are considered to be recoverable. Variations in data on recycling, therefore, do not lead to large variations in the overall results. Nevertheless, if on the long term the recycling structure for PLA would be expanded, the performance of recycling will become more important. For illustration, if $100 \%$ of PLA wastes are recycled and after their second use incinerated with energy recovery, energy savings of the total bio-refinery chain would double and costs would decrease more than $70 \%$ resulting in net profits of PLA production from short rotation wood.

Unlike recycling, the substitution of petrochemical polymers plays an important role in the overall energy savings and GHG emission reductions. Non-renewable energy consumption of the production of petrochemical polymers and energy recovery from their incineration can be quite different depending on the kind of polymer produced and the waste treatment system applied. It should be noted that the precise type of material to be substituted by a new product could not be defined exactly. This is due to the fact that biobased polymers will replace several materials depending on the technological substitution potentials for specific applications and the market prices of competing materials. As a consequence, a mix of materials will be substituted. For example, PLA is suitable to replace Nylon 6 (Crank et al., 2004), which has comparably high gross energy requirements for its production but also high lower heating values (APME, 2003a). If the PLA produced in the bio-refinery system would replace Nylon 6 instead of HDPE and PET, the total energy savings would increase about 5-10\% compared to the base case.

With regard to substitution, also is the use of factors to convert energy consumption to non-renewable fuel consumption and GHG emissions play a role. While in this study European mixes of energy sources are made use of, for some aggregated data sets used in this study, e.g. data sets of fodder products, different energy mixes might have been drawn on. However, these differences do not influence the overall results significantly.

Vink et al. (2003) state fossil energy consumptions for PLA production. Producing PLA from corn (without recovering energy from biomass residues) uses about $54 \mathrm{MJ} / \mathrm{kg}$ PLA. PLA production from lingo-cellulose, i.e. corn stalk, with steam use from lignin combustion leads to fossil energy consumptions of $29 \mathrm{MJ} / \mathrm{kg}$ PLA. The results of our study are for the PLA production process based on the study of Vink et al. (2003). However, our study applies different data for the mix of primary energy sources and biomass production. Furthermore, the use of steam and electricity from biomass residues in the production of PLA is taken into account for both wheat and short rotation wood. Because of this bio-energy use, respective non-renewable energy consumptions of PLA production from cradle-to-factory-gate are lower, i.e. $28 \mathrm{MJ}_{\text {prim }} / \mathrm{kg}_{\mathrm{PLA}}$ for the production using wheat and $23 \mathrm{MJ}_{\text {prim }} / \mathrm{kg}_{\mathrm{PLA}}$ for the production using short rotation wood. Including the savings from recycling and waste incineration, these values are even lower, i.e. $20 \mathrm{MJ}$ prim $/ \mathrm{kg}_{\mathrm{PLA}}$ for wheat and $14 \mathrm{MJ}_{\text {prim }} / \mathrm{kg}_{\text {PLA }}$ for short rotation wood.

A disadvantage of our approach using own-price elasticity from literature is that elasticity factors do not refer specifically to a product from the bio-refinery or to a specific type of 
agricultural land. Therefore, own-price elasticity figures used in this study are uncertain, but influence the result significantly as shown in the sensitivity analysis in Section 4.2. The approach presented in this study is, therefore, first of all a methodological demonstration of incorporating market effects in the analysis. It should also be noted, that our analysis refers to a situation in which the introduction of PLA production is planned externally. Therefore, market adjustment mechanisms such as adapting the PLA production capacity to its supply curve are not included. Instead, the analysis shows the limited capacity of the market for this particular GHG mitigation option.

\section{Conclusions}

This paper investigates non-renewable energy consumptions, GHG emissions and costs of bio-refinery systems for PLA production in comparison to a conventional mainly fossil fuel based production system. The analyses provide a good insight into the mechanisms that influence the performance of bio-refinery systems. As a result the contribution of 'multifunctional' components to the performance of the overall bio-refinery could be identified.

It is concluded that bio-energy production from biomass residues can contribute significantly to savings of non-renewable energy consumption and GHG emission reduction. The benefits from by-product use, however, are very small with the largest benefit in a reduction of overall system costs. Therefore, the expected benefits of bio-refineries that would be obtained by producing a range of products are not found in the case of PLA production, because by-products are relative low value fodder products. Recycling and waste treatment with energy recovery play an important role in the reduction of non-renewable energy consumption and GHG emissions, but are less important than bio-energy production from biomass residues. If much larger recycling rates of back-to-monomer recycling would become possible by setting up a thorough (and probably costly) structure to collect PLA waste, recycling could result in very large benefits with regard to energy savings and GHG emission reductions.

From the analysis, most favourable options of the investigated PLA bio-refinery system emerged. Intensive crop production systems on high quality land are favourable with regard to energy savings and GHG emission reductions, while non-intensive crop production systems are more favourable with regard to cost. While this conclusion is true for the Polish agricultural system, for other countries with a different relation between crop production costs and yields it might diverge. Moreover, fibre production replacing PET as petrochemical reference polymer is better than packaging production replacing HDPE. Waste incineration with energy recovery is better than digestion with energy recovery with regard to energy savings, GHG emission reduction and costs. The production of PLA from short rotation wood compared to PLA production from wheat is better in view of energy savings and GHG emission reduction and much better with respect to economic performance.

All PLA bio-refinery systems lead to net savings of non-renewable energy consumption of up to $220 \mathrm{GJ} /($ ha yr), from which about $30-60 \%$ relate to multi-functional elements, i.e. energy production from biomass residues, by-product use, recycling of PLA, and energy recovery from PLA waste. Besides, all options regarded lead to net GHG emis- 
sion reduction with reductions of up to $17 \mathrm{~kg} \mathrm{CO}_{2 \mathrm{eq}} /$ (ha yr) and a contribution of $20-60 \%$ of multi-functional elements to these reductions. Contrary to GHG emission reductions and energy savings, most PLA bio-refinery systems considered in this study lead to net costs of up to $4600 € /($ ha yr). Only $5-20 \%$ of the revenues in the overall bio-refinery system result from multi-functional elements. However, PLA production from lingo-cellulose leads to net benefits if a high amount of the high-value product fibre is produced or a high amount of PLA is recycled.

Under Polish conditions, the profitability of PLA production depends strongly on the market price of PLA products. This market price can change due to the kind of application, fluctuations on the market, price elasticity with increasing production capacity, etc. If it is taken into account, that PLA prices are likely to decrease if the production capacity is increased, it has been shown that the decrease of costs of PLA bio-refinery systems due to economies of scale is marginal at large scales. For example, overall costs not taking into account economies of scale increase about $3 \%$ if the market volume is doubled with the base assumptions of elasticity used here. The shape of costs versus scale is very sensitive to the own-price elasticity of PLA.

Land costs are not an important element in the total costs of a PLA bio-refinery system. However, considering own-price elasticity of land, land rents increase significantly, even at moderate scales of biomass production. Consequently, these changes of land prices can become very significant if the use of biomass for energy or materials, e.g. for bio-refineries, is introduced on a large scale.

Summarising, a multi-functional use of biomass feedstock is necessary to achieve a viable PLA bio-refinery systems with regard to saving of non-renewable energy consumption and GHG emission reduction. However with regard to costs, the multi-functional use only shows a small contribution to overall profits. Own-price elasticity of material markets is crucial for the economic performance of PLA bio-refinery systems. A more detailed analysis of material markets is desirable in order to quantify these effects more precisely.

\section{Acknowledgements}

The authors are grateful for funding by NOW/SenterNovem. The authors also would like to thank Dr. Frank Vöhringer (Wageningen University, Environmental Economics and Natural Resources) for his helpful comments. Drs. Jinke van Dam (Utrecht University, Copernicus Institute) is gratefully acknowledged for her advice on Polish agriculture.

\section{References}

AAc. Eco-profile of starch. Summary Report. Association des Amidonneries de Céréales de l'Union Européenne; 2001.

Aden A, Ruth M, Ibsen K, Jechura J, Neeves K, Sheehan J, et al. Lignocellulosic biomass to ethanol process design and economics utilizing co-current dilute acid prehydrolysis ad enzymatic hydrolysis for corn stover. Golden: NREL; 2002.

Annetts JE, Audsley E. Modelling the value of a rural biorefinery. Part I. The model description. Agric Syst 2003;76:39-59. 
AOO. Mileueffectrapport Landelijk Afvalbeheerplan. Achtergronddocument A 14 Uitwerking "GFT-afval”, Afval Overleg Orgaan, Utrecht; 2002.

APME. Eco-profiles of the European plastics industry; 2003a.

APME. Plastics-an analysis of plastics consumption and recovery 2001\&2002; Summer 2003b.

Azar C, Berndes G. The implication of carbon dioxide abatement policies on food prices. In: Dragun AK, Tisdell $\mathrm{C}$, editors. Sustainable agriculture and environment-globalisation and the impact of trade liberalisation. Cheltenham, UK: Edward Elgar; 1999. p. 153-70.

Benjamin, Y, van Weenen, H. Design for sustainable development-crops for sustainable enterprise. Commissioned by European Foundation for the Improvement of Living and Working conditions, Environmental Design for Ecological Need (EDEN), International Design and Environmental Activities, Dublin; 2000.

Biewinga EE, van der Bijl G. Sustainability of energy crops in Europe. Utrecht, The Netherlands: CLM; 1996.

Brandrup J, Immergut EH, Grulke EA, Abe A, Bloch DR. Polymerhandbook. 4th ed. New York: Wiley; 1999.

Carlsson-Kanyama A, Faist M. Energy use in the food sector: a data survey. Stockholm: Stockholm University; 2000.

Cefic. Petrochemistry in Western Europe-facts 2003. http://www.petrochemistry.net (accessed January 2004); 2003.

Ciaian P, Swinnen W, Münch W. The impact of the common agricultural policy on income distribution and welfare in Central and Eastern European countries. In: Proceedings of the fifth international workshop on European economy; 2002.

CIRFS. Man-made fibre production, Comité International de la Rayonne et des Fibres Synthétiques, Brussel; 2002.

Clarinval A-M. Classification and comparison of thermal and mechanical properties of commercialised biodegradable polymers. In: IENICA, editor. Proceedings of the bioplastics work; 2002.

Crank M, Patel MK, Marscheider-Weidemann F, Schleich J, Hüsing B, Angerer G. Techno-economic feasibility of large-scale production of bio-based polymers in Europe (PRO-BIP), report commissioned by European Commission Institute for Prospective Technological Studies (IPTS), published by: Department of Science, Technology and Society, Copernicus Institute, Utrecht University/Fraunhofer Institute for Systems and Innovation Research (FhG-ISI), Utrecht, The Netherlands/Karlsruhe, Germany, October 2004, 231 pp.

CSO. Concise statistical yearbook of Poland. Warsaw, Poland: CSO; 2003.

DHV. Waste management policies in Central and Eastern European countries: current policies and trends. Prague, Czech Republic: DHV; 2001.

DOE. Renewable energy technology characterizations. Biomass technologies. USA: Department of Energy/EPRI; 1997.

Dornburg V, Temeer G, Faaij A. Economic and greenhouse emission analysis of bio-energy production using multi-product crops-case studies for The Netherlands and Poland. Biomass and Bioenergy 2005;28:454-74.

Dornburg V, Faaij APC. Costs and $\mathrm{CO}_{2}$ emission reductions of biomass cascading-methodological aspects and case study of SRF poplar Clim Change 2005;71(3):373-408.

Dornburg V, Faaij A. Efficiency and economy of wood-fired biomass energy systems in relation to scale regarding heat and power generation using combustion and gasification technologies. Biomass and Bioenergy 2001a;21:91-108.

Dornburg, V, Faaij, A. Scenario-ontwikkeling voor de optimalisatie van energieproductie uit afvalstoffen in Nederland, report NWS-E-2001-01, STS, Utrecht University; 2001b.

Dornburg V, Lewandowski I, Patel M. Land requirements, energy savings and greenhouse gas emissions reduction of bio-based polymers compared to bioenergy — an analysis and system extension of LCA studies. J Ind Ecol 2003;7(3/4).

DTO. Geintegreerde plantconversie. In: DTO, editor. Duurzame Technologische Ontwikkeling Chemie; vijf technologie ontwikkelingsvelden. Den Hague, The Netherlands: Willems \& Van den Wildenberg; 1997.

EC. Green paper: towards a European strategy for the security of energy supply. European Comission COM(2000) 769 final; 2000.

ECN. PHYLLIS—database for biomass and waste. Energy Research Foundation ECN, Petten, The Netherlands ECN. http://www.ecn.nl/Phyllis (access 2003); 2003.

Eggels PG, Ansems AMM, van der Ven BL. Eco-efficiency of recovery scenarios of plastics packaging. Apeldoorn, The Netherlands: TNO; 2001.

Elliot DC. Chemicals from biomass. In: Cleveland CJ, editor. Encyclopedia of energy. Elsevier; 2004. 
Faaij, A, Meuleman, B, Ree, RV. Long term perspectives of BIG/CC technology, NOVEM EWAB 9840, Novem, Utrecht, The Netherlands; 1998.

Fan Y, Nishida H, Shirai Y, Endo T. Racemization on thermal degradation of poly(L-lactide) with calcium salt en structure. Polym Degrad Stab 2003;80:503-11.

FAO. Fertilizer use by crop in Poland. Rome: FAO; 2003.

Franssen S. MATTER 3.0: relaxing the demand in the MATTER model. Petten, The Netherlands: ECN; 1999.

Garlotta D. A literature review of poly(lactic acid). J Polym Environ 2001;9:63-84.

Gielen DJ, Bos AJM, de Feber MAPC, Gerlagh T. Biomass For Greenhouse Gas Emission Reduction Task 8: optimal emission reduction strategies, Land for Western Europe. Petten, The Netherlands: ECN; 2000.

Gielen D, Fujino J, Hashimoto S, Moriguchi Y. Modeling of global biomass policies. Biomass and Bioenergy 2003;25:177-95.

Green C. Potential scale-related problems in estimating the costs of $\mathrm{CO}_{2}$ mitigation policies. Climatic Change 2000;44:331-49.

Gruber P, O’Brien M. Polylactides NatureWorks ${ }^{T M}$ PLA. In: Doi Y, Steinbüchel A, editors. Biopolymers. Weinheim, Germany: Wiley/VCH; 2002. p. 235-49.

Hamelinck, CH. Advanced biofuels, PhD Thesis. STS, Utrecht University; 2004.

Hydro Agri Dülmen GmbH. Faustzahlen für Landwirtschaft und Gartenbau, Duelmen. Münster, Germany: Verlagsunion Agrar; 1993.

IEA. $\mathrm{CO}_{2}$ emissions from fuel combustion 1971-2000. Paris, France: International Energy Agency; 2002.

Kreutz TG, Larson ED, Consonni S. Performance and preliminary economics of black liquor gasification combined cycles for a range of kraft pulp mill sizes. In: Proceedings of the TAPPI international chemical recovery conference; 1998.

Kumar A, Cameron JB, Flynn PC. Biomass power cost and optimum plant size in western Canada. Biomass and Bioenergy 2003;24:445-64.

Leaversuch R. Renewable PLA polymer gets 'Green Light' for packaging use. Plastictechnology 2002.

Mann M, Spath P. Life cycle assessment of a biomass gasification combined-cycle power system. Golden, USA: NREL; 1997.

McAloon A, Taylor F, Yee W, Ibsen K, Wooley R. Determining the costs of producing ethanol from corn starch and lignocellulosic feedstocks. Golden, USA: NREL; 2000.

NRC. Biobased industrial products—priorities for research and commercialization. Washington, DC, USA: National Academy Press; 1999.

Patel M, Bastioli C, Marini L, Würdinger E. Life cycle assessment of biobased polymers and natural fiber composites. In: Doi Y, Steinbüchel A, editors. Biopolymers. Weinheim, Germany: Wiley/VCH; 2002. p. 409_ 52 .

Scott DS, Lamarre P, Tsang W, Piskorz J, Radlein D. Feasibility study for a biomass refinery concept. In: van Overend RP, Chornet E, editors. Proceeding of the third biomass conference of the Americas, Making a business from biomass in energy, environment, chemicals, fibers, and materials. Pergamon Press; 1997. p. 933-45.

Skarzynska, A, Augustynska-Grzymek, I. Koszty Jednostkowe I Dochodowosc Produkcji Rolniczej W Gospodarstwach Indywidualnych W 2000 Roku, IER, IGZ, Warszawa, Poland; 2000.

Szczukowski, S, Kisiel, R, Piechocki, J, Tworkowski, J, Stolarski, M. Energetic efficiency of production of short rotation willow coppice, University of Warmia and Mazurin; 2001.

Szczukowski S, Tworkowski J, Kwiatkowski J. Możliwości wykorzystania biomasy Salix sp. pozyskiwanej z gruntów ornych jako ekologicznego paliwa oraz surowca do produkcji celulozy i płyt wiórowych. Postępy Nauk Rol 1998;2:53-63.

Södergård A, Stolt M. Properties of lactic acid based polymers and their correlation with composition. Prog Polym Sci 2002;27:1123-63.

Suurs R. Long distance bioenergy logistics: an assessment of costs and energy consumption for various biomass energy transport chains. STS, Utrecht University; 2002.

Tsuji H, Daimon H, Fujie K. A new strategy for recycling and preparation of poly(L-lactic acid): hydrolysis in the melt. Biomacromolecules 2003;4:835-40.

UBA. Basisdaten Umweltmanagement. Umweltbundesamt, Berlin, Germany; 2003. http://www. umweltbundesamt.de/uba-info-daten/daten/baum/ (access year 2003).

UN. Industry Commodity Production Statistic Database 1950-2000, UN; 2002. 
van den Broek R, Faaij A, van Wijk A. Biomass combustion power generation technologies. In: European Commission (Ed.), Energy from biomass-an assessment of two promising systems for energy production. JOU2-CT93-0397; 1995.

van der Lans RP, Pedersen LT, Jensen A, Glarborg P, Dam-Johansen K. Modelling and experiments of straw combustion in a grate furnace. Biomass and Bioenergy 2000;19:199-208.

Vink ETH, Rabago KR, Glassner DA, Gruber PR. Applications of life cycle assessment to NatureWorks ${ }^{\mathrm{TM}}$ polylactide (PLA) production. Polym Degrad Stab 2003;80:403-19.

Vöhringer, F. Environmental Economics and Natural Resources, Wageningen University, Personal communication; January 2004.

VVAV. Handboek Afvallogistiek, Drukkerij Peter Szulc. Utrecht, The Netherlands: VVAV; 1994.

Walsh ME. Method to estimate bioenergy crop feedstock supply curves. Biomass and Bioenergy 2000;18:283-9.

Wiltsee, G. Lessons learned form existing biomass power plants. NREL/SR-570-26946, NREL, Golden, USA; 2000.

Wooley R, Ruth M, Sheehan J, Ibsen K, Majdeski H, Galvez A. Lignocellulosic biomass to ethanol - process design and economics utilizing co-current dilute acid prehydrolysis and enzymatic hyrolysis - current and futuristic scenarios. Golden, USA: NREL; 1999.

Würdinger, E, Roth, U, Wegener, A, Peche, R. Kunststoffe aus nachwachsenden Rohstoffen: Vergleichende Ökobilanz für Loose-fill-Packmittel aus Stärke bzw. Polystyrol, BIFA, IFEU, Flo-Pak; 2002.

Wyman CE. Potentials synergies and challenges in refining cellulosic biomass to fuels, chemicals and power. Biotechnol Prog 2003;19:254-62.

Zeevalkink JA, van Ree R. Conversietechnologieen voor de productie van elektriciteit en warmte uit biomassa en afval. Utrecht, The Netherlands: Novem; 2000. 